\title{
Supramolecular Biopolymers for Tissue Engineering
}

\author{
Rosario Pérez-Pedroza $\mathbb{D},{ }^{1}$ Alan Ávila-Ramírez $\mathbb{D},{ }^{1}$ Zainab Khan $\mathbb{D},{ }^{2}$ Manola Moretti $\mathbb{D},{ }^{1}$ \\ and Charlotte A. E. Hauser (D) ${ }^{1}$ \\ ${ }^{1}$ Laboratory for Nanomedicine, Division of Biological \& Environmental Science \& Engineering (BESE), King Abdullah University of \\ Science and Technology (KAUST), Thuwal 23955-6900, Saudi Arabia \\ ${ }^{2}$ Beacon Development, King Abdullah University of Science and Technology (KAUST), Thuwal 23955-6900, Saudi Arabia
}

Correspondence should be addressed to Charlotte A. E. Hauser; charlotte.hauser@kaust.edu.sa

Received 16 September 2020; Revised 11 December 2020; Accepted 27 December 2020; Published 13 January 2021

Academic Editor: Grissel T. De Santiago

Copyright ( $\odot 2021$ Rosario Pérez-Pedroza et al. This is an open access article distributed under the Creative Commons Attribution License, which permits unrestricted use, distribution, and reproduction in any medium, provided the original work is properly cited.

\begin{abstract}
Supramolecular biopolymers (SBPs) are those polymeric units derived from macromolecules that can assemble with each other by noncovalent interactions. Macromolecular structures are commonly found in living systems such as proteins, DNA/RNA, and polysaccharides. Bioorganic chemistry allows the generation of sequence-specific supramolecular units like SBPs that can be tailored for novel applications in tissue engineering (TE). SBPs hold advantages over other conventional polymers previously used for TE; these materials can be easily functionalized; they are self-healing, biodegradable, stimuli-responsive, and nonimmunogenic. These characteristics are vital for the further development of current trends in TE, such as the use of pluripotent cells for organoid generation, cell-free scaffolds for tissue regeneration, patient-derived organ models, and controlled delivery systems of small molecules. In this review, we will analyse the 3 subtypes of SBPs: peptide-, nucleic acid-, and oligosaccharide-derived. Then, we will discuss the role that SBPs will be playing in TE as dynamic scaffolds, therapeutic scaffolds, and bioinks. Finally, we will describe possible outlooks of SBPs for TE.
\end{abstract}

\section{Introduction}

Supramolecular biopolymers (SBPs) are polymeric units derived from macromolecules that can assemble with each other by noncovalent interactions. Independent units of an SBP interact with each other to create vast structural arrays [1-3]. In fact, it is common to find supramolecular assemblies within biological systems because macromolecules intrinsically interact among each other by noncovalent bonding. Thanks to the advancement of bioorganic chemistry [4-6], researchers have been able to synthesize short strands of sequence-specific SBPs. By doing so, they can regulate the governing noncovalent forces by tuning the monomers' sequence. These changes also affect the topological features of the SBP. In other words, if the sequence changes, the weak interactions will change the microstructure and accordingly the macrostructure $[1,7,8]$. Furthermore, as sequences change, specific motifs or active sites may become available for the interaction between the material and its environment. Hence, SBPs have the potential to embody tailored materials for different applications, such as scaffolds for tissue engineering (TE).

$\mathrm{TE}$ and regenerative medicine are multidisciplinary fields that target the development and generation of functional tissues and organs, therapies, and technologies to renew damaged tissues. TE relies on the encapsulation and culture of cells in a scaffold that can sustain its growth to recreate the microenvironment commonly found in a tissue of interest. TE holds a grand promise for research and clinical applications. It could allow the advancement of patient-specific personalized therapies, sophisticated tissue generation, miniaturization of functional organs, accelerated therapeutic evaluation, and even reduced animal use [9]. Currently, the state-of-the-art of TE is switching from simple in vitro replicas of tissue sections to structurally and biologically complex models of whole organs [10-12]. Researchers are also 
developing dynamic and cell-free scaffolds for regeneration [13-15], patient-derived organ models [16], and more elegant molecular delivery systems $[17,18]$.

SBPs have a variety of advantages when used in TE. First, their sequence is tunable when synthesized by solid-phase synthesis. Several experts have already identified interactive motifs for assembly [19-22]. Tailoring SBPs is not only limited to the polymeric unit and the structure per se but also includes any bioactive motifs that could be incorporated within the same unit or structure, creating multifunctional materials [23]. Furthermore, some SBPs are thermodynamically reversible, which allows them to constantly heal and reshape their structure at the nanoscale [24-26]. Hence, SBPs also allow the incorporation of controlled chemical and physical degradation mechanisms within the materials. All these characteristics allow researchers to tailor SBPs into stimuliresponsive materials, also known as smart materials [27, 28]. Finally, SBPs can combine all these smart properties into conventional materials. In summary, SBPs are easily functionalized to induce specific cell responses. Furthermore, as shown in Figure 1, the specific sequence of each monomer defines the noncovalent interaction for assembly, as well as its specific nano- and microstructure. These scaffolds can be further implemented as bioinks, drug delivery systems, and dynamic or therapeutic scaffolds.

It is important to note that the use of synthetic polymers and biopolymers was pivotal to kick-start the development of TE. Conventional polymers allowed to generate threedimensional (3D) models that resembled natural tissue conformations, concluding that two-dimensional cell cultures are unable to recapitulate the characteristics of most tissues [29-31]. This is because conventional polymeric scaffolds support cellular seeding, proliferation, migration, and differentiation in a $3 \mathrm{D}$ geometry. Also, these materials allow gas and mass transport, water retention, physical support, and physical cell aligning $[32,33]$. However, conventional polymers present a variety of disadvantages to novel technologies such as the use of organoids [34, 35], whole-organ engineering [36, 37], patient-specific tissue regeneration [38], and in situ therapeutics [39]. Specifically, conventional polymers are rarely stimuli-responsive, do not self-heal, do not degrade in a controlled manner, and are expected to trigger unwanted immune responses, unless thoroughly functionalized. Moreover, conventional polymers due to their lack of resemblance to biological molecules are not equipped with the benefits that SBPs have. Conventional polymers commonly rely on the scaffold enrichment with specific molecules, responsive moieties, or chemical functionalization by surface chemistry $[40,41]$. With either approach, signals or functional moieties could have nonspecific and uncontrolled localization and delivery, requiring extra steps for the functionalization or enrichment of the polymer [42, 43]. Furthermore, a majority of the conventional polymers fails to remodel and heal themselves continuously in tune with complex cellular structures, unless coupled with self-healing systems or moieties [44, 45]. This issue becomes important when pluripotent cells are used in TE for differentiation and self-organization into multiple cell types in order to resemble the natural tissue. Different from biopolymers, conventional polymers fail to constantly remodel their nanostructure to be adapted to the growth and self-organizing of these cellular constructs [46, 47]. Similarly, the scaffolds are expected to have a controlled degradation that slowly allows cells to exchange the matrix scaffold to their own extracellular scaffold materials [48, 49]. Degradation of conventional polymers has variable kinetics, proportional to the water diffusion coefficient, rate of hydrolysis, and the thickness of the construct. All these parameters are difficult to control in order to match the degradation rate and the ECM reconstruction rate of the cells.

The concept of "supramolecular units" was coined in the 1960s by Nobel Laureate Albert Szent-Gyorgyi [50], 40 years after Hermann Staudinger's definition of a polymer [51]. Szent-Gyorgyi described the assembly of protein structures as the covalently bonded molecular bricks with "submolecular" characteristics that are interacting with each other to form supramolecular units. As mentioned previously, the interactions that define the assembly of supramolecular units are the "cooperation of hydrogen bonding and hydrophobic bonding" [52] among proteins and nucleic acids. Interestingly, in 1963, Merrifield developed the method of solidphase peptide synthesis (SPPS), which simplified the synthesis of sequence-specific polypeptides [53-56]. Since then, similar efforts to ease the synthesis of other sequencespecific biopolymers were consequently proposed [57-59]. All these discoveries and developments allowed the synthesis of sequence-specific polypeptides, nucleic acid chains, and polysaccharides at high-purity rates, which eventually provided the versatility to use these molecules as selfassembling materials with interesting properties at the nanoscale. Currently, there is enough evidence that SBPs can be used, together with other tools, as advanced biomaterials for TE, as shown in Figure 2.

The forces driving SBPs' assembly involve several noncovalent interactions that act cooperatively. The strength and participation of each vary depending on the specific sequence of the SBPs $[69,70]$. Nucleic acid-derived materials hold the simplest assembling mechanics among other SBPs, as the units interact initially by base pairing held by $\mathrm{H}$-bonds. Canonical Watson-Crick base pairing and noncanonical base pairing (Hoogsteen and wobble base pairs, commonly found in RNA molecules) occur thanks to hydrogen- ( $\mathrm{H}-)$ bonds formed among bases. All these interactions are based on the principle of complementarity [71]. However, it is widely accepted that nucleic-acid-derived SBPs can be further stabilized by $\pi-\pi$ stacking through the aromatic structures of the nucleobases in the same backbone $[72,73]$. In fact, it is the $\pi-\pi$ interactions that stabilize the DNA structures towards the typical double-helical structure. On the other hand, RNA molecules will be mainly stabilized by the tertiary structures facilitated by the H-bonding between the bases [74].

Peptide-derived materials have a higher degree of complexity than nucleic-acid-derived materials due to the characteristics of their amino acids' side-chain residues [75-78]. One of the important parameters used to design amphiphilic peptides is the existence of a gradient of polarity $[76,79,80]$. Nonpolar residues aggregate with each other due to hydrophobic interactions, while still maintaining solubility due to the presence of polar residues. As hydrophobic interactions 


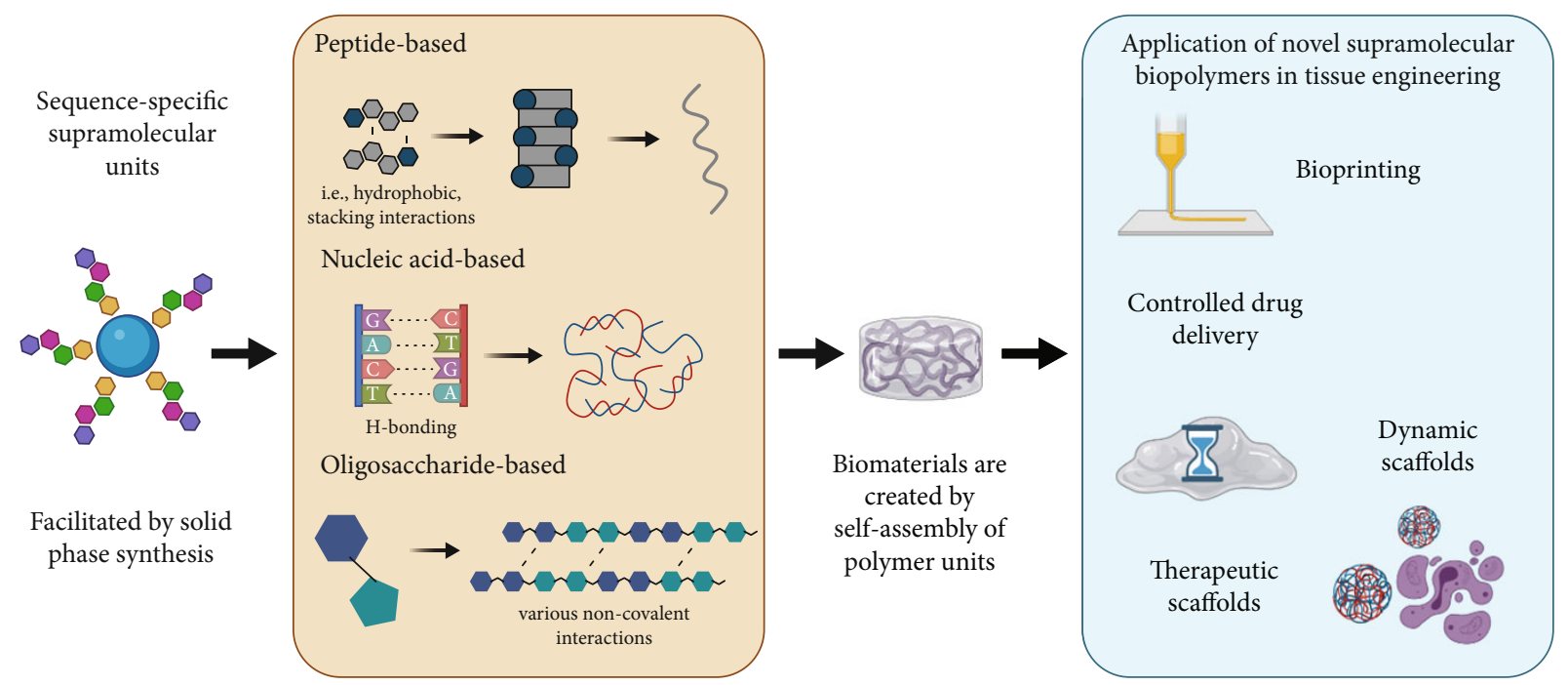

Figure 1: The technology of solid-phase synthesis eased the generation of sequence-specific units for supramolecular assemblies. These sequence-specific units interact with each other by varied noncovalent interactions, which leads to the assembly of nano- and microscopic structures that develop into macroscale sized biomaterials, such as hydrogels. These supramolecular assemblies can be used as novel biopolymers for tissue engineering, as their properties allow them to be used as bioinks, as carrier for controlled drug delivery, and as dynamic and therapeutic scaffolds.

spontaneously arise from entropy-driven changes, the use of charged and polar residues induces additional ionic interactions and $\mathrm{H}$-bonding, whereas amide- $\pi$ and $\mathrm{CH}-\pi$ interactions can further contribute to noncovalent interactions [81]. The velocity in which the one or other system is reached will define the characteristics of the self-assembling peptide. Generally speaking, most peptides have a cooperative and enthalpy-driven $\mathrm{H}$-bonding that induces hydrophobic aggregation, plus complementary interactions that will aid on the control of hydrophobicity rates [82]. Interestingly, the assembly of peptides tends to follow a nucleation pattern. Once the energy barrier for aggregation is broken, the microstructure will assemble around already aggregated dimers.

Oligosaccharide-derived peptides have the most complex set of noncovalent interactions. Some researchers report on self-assembly mechanisms similar to those of the polymeric version of the oligosaccharide, such as ionic bonds in oacetylated alginate [83]. However, some other SBPs include oligosaccharides modified to include an aliphatic section in the molecule. The resultant amphiphilic molecules assemble by hydrophobic interactions, like peptide-based SBPs. One of the most recognized supramolecular oligosaccharide is the family of cyclodextrins, which interact by the so-called host-guest interactions. These interactions are based on the existence of a lipophilic cavity and a hydrophilic exterior that allows for the capture of hydrophobic molecules in the inside of a donut-shaped structure $[84,85]$.

In this review, we want to discuss the three types of SBPs used for TE: peptide-, nucleic acid-, and oligosaccharidederived polymers. We will point to a variety of interesting approaches that have been generated for the development of novel materials with potential applications in TE. In addition, we elaborate on the challenges in TE that could be overcome with these materials. How are these materials currently being used as dynamic and therapeutic scaffolds. Finally, we will talk about the potential of these materials in bioprinting, and we will give an outlook about the field. It is important to note that besides supramolecular biopolymers, supramolecular assemblies can also rely on organic or inorganic moieties. However, given that this field is very broad, our focus will be on the specific concepts surrounding supramolecular biopolymers (SBPs).

\section{Applications}

2.1. Peptide-Derived Polymers. Noncovalent interactions such as hydrophobic effects, electrostatic interactions, and $\pi-\pi$ stacking influence peptide assembly [82]. These weak bonds affect the interactions among residues, which eventually define the formation of stable three-dimensional structures similarly as during the folding of proteins. Specific peptide compounds with a characteristic and defined sequence and short enough to make folding difficult or impossible are able to self-assemble with each other; these compounds are known as self-assembling peptides (SAP) and have been thoroughly studied for almost 30 years. Studies on peptide assembly started in the early 90 s, with two peptide sequences that would naturally create simple $\beta$-sheets. The first pioneering study started with a Z-DNA-binding protein from Saccharomyces cerevisiae. After exploring its composition, Zhang et al. found that a repetitive motif, known as EAK16, was able to self-assemble [86, 87]. Investigations on the second self-assembling peptide ever explored started in 1993, with the study of amyloid-beta peptides that promote degeneration in Alzheimer's disease [88, 89]. Soon after, peptide aggregates were proposed as a model system to study self-assembly mechanisms [90], and by 1997, a 24residue peptide sequence was proved capable of assembling in $\beta$-sheet plates [91]. These studies started the emergence of SAPs as potential materials for TE. 

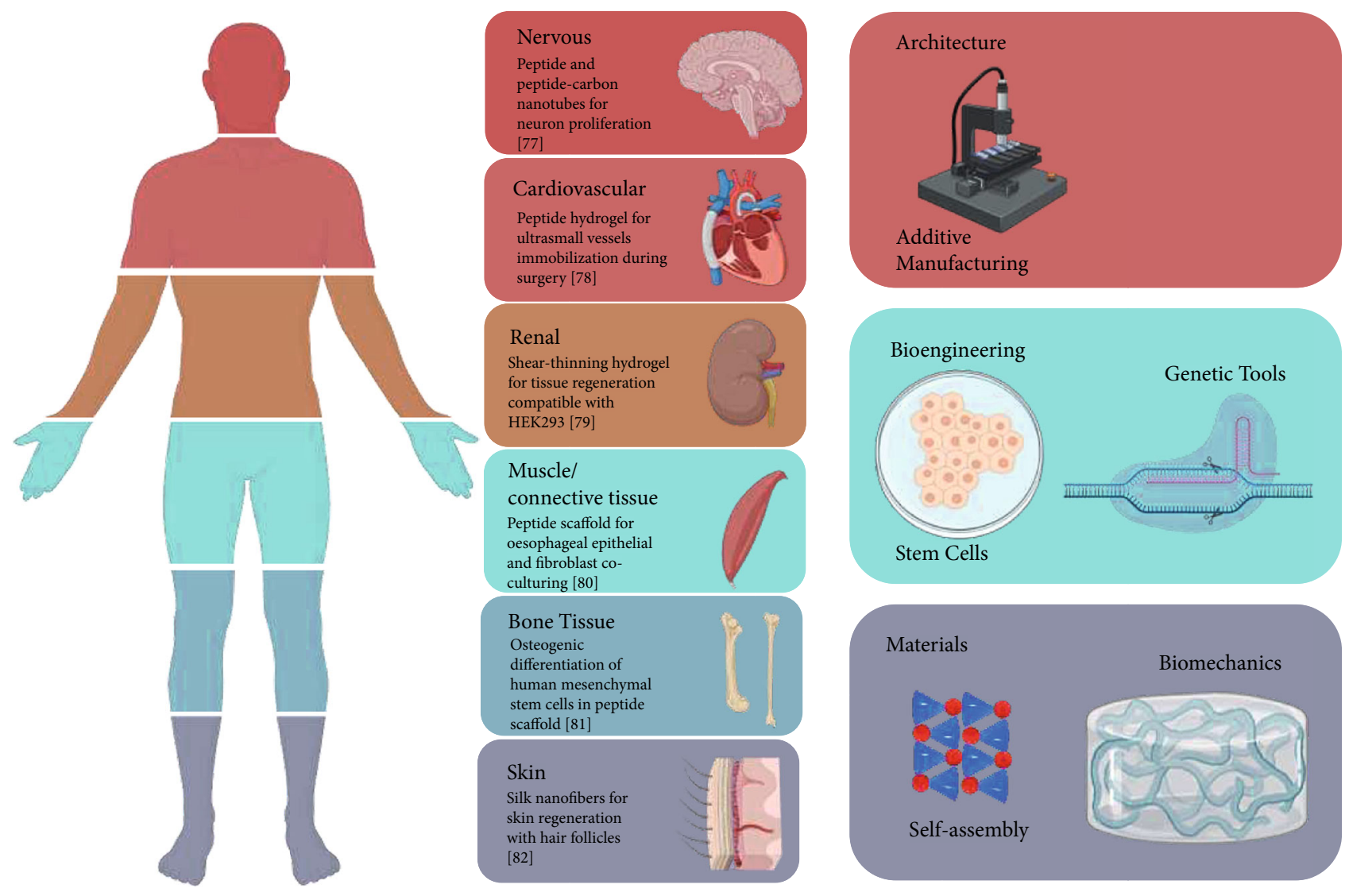

FIGURE 2: TE is built on the following important pillars comprised of the development of organ and tissue architecture, bioengineering techniques, and material science. SBPs are involved in all these three pillars of TE with the aim to develop tissue-specific constructs for a variety of complex human organ systems; nowadays, SBPs have proven resourceful for the proliferation of neurons [60], endothelial cells [61], kidney cells [62], fibroblasts [63], osteocytes from mesenchymal stem cells [64], and complex skin regeneration [65]. SBPs can be used cooperatively with other technologies to create versatile and smart scaffolds for TE. For instance, in order to obtain complex architectures, SBPs can be coupled with additive manufacturing techniques [66]. SBPs can also be coupled with bioengineering tools such as the use of stem cells [67] to create complex tissue-like cultures or the use of genetic tools to create active therapeutic scaffolds [68]. Finally, these materials can be designed to have triggered assembly mechanisms [26], as well as to control cell mechanics by their structural composition [23].

Evidence was given that peptides aggregate into a variety of nanostructures such as bilayers, nanotubes, nanorods, nanovesicles, nanofibers, nanobelts, and nanodonuts [2]. Hauser's work is explicitly focused on developing peptide nanofibers because of their similarity to fibril structures formed within the native extracellular matrix (ECM). For instance, the Hauser group previously designed peptide biomaterial that exhibits a fibrous structure in which individual nanofibers can extend up to one centimeter in length. To this effect, it is proposed that the use of materials that resemble the ECM may trigger specific cellular responses such as microvilli formation in intestinal epithelial cells, which is a direct response to the interaction between the cell and the surface topography $[92,93]$. Indeed, fiber-forming decellularized matrices and collagen are the typical scaffolds used for the formation of intestinal villi. However, some SAPs designed by Loo et al. are among the few materials that also allow villi formation, presumably due to the nanofiber conformation of the structure (Figures 3(a)-3(c)) [66]. In fact, fiber-forming SAPs recapitulate the cellular microenviron- ment so that encapsulated stem cells can maintain pluripotency in long-term cultures for over 30 passages without major chromosomal mutations [67].

Moreover, the versatility of SAPs is not only limited to their biofunctionality but also to the possibility to tune their mechanical properties. Chan et al. developed an SAP in which the C-terminal residue of the hexapeptide Leu-IleVal-Ala-Gly-Xaa (where Xaa could be any amino acid) will determine the mechanical properties of the material, the clarity of the hydrogel, and the condensation morphology of the nanofiber without affecting the cytocompatibility of the gel (Figure 3(d)). The inclusion of an arginine residue at the Cterminus enhances gelation kinetics due to the presence of hydrogen bond donors/acceptors. However, a residue that is a weak donor/acceptor, like lysine, will allow the peptide to diffuse before condensing, permitting gelation at lower concentrations [75]. This work proves that peptide-derived SBPs are not only bioactive but can also be tuned in a bottom-up fashion by partially modifying an SAP sequence. This implication may allow the use of bioactive materials 


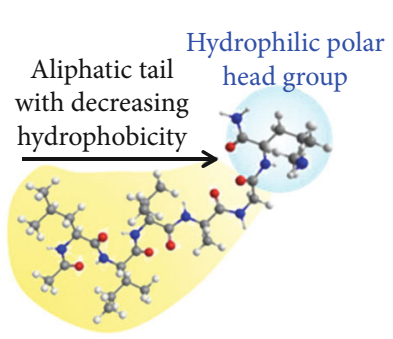

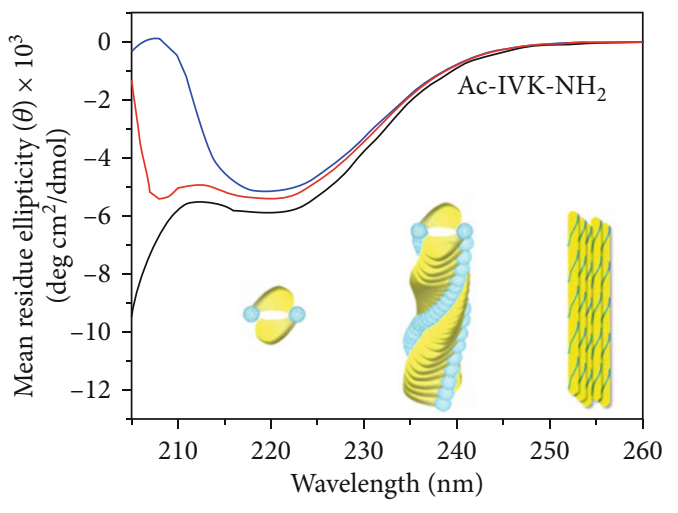

$$
\begin{gathered}
-0.1 \mathrm{mg} / \mathrm{mL} \\
-0.65 \mathrm{mg} / \mathrm{mL} \\
-1.3 \mathrm{mg} / \mathrm{mL}
\end{gathered}
$$

(a)
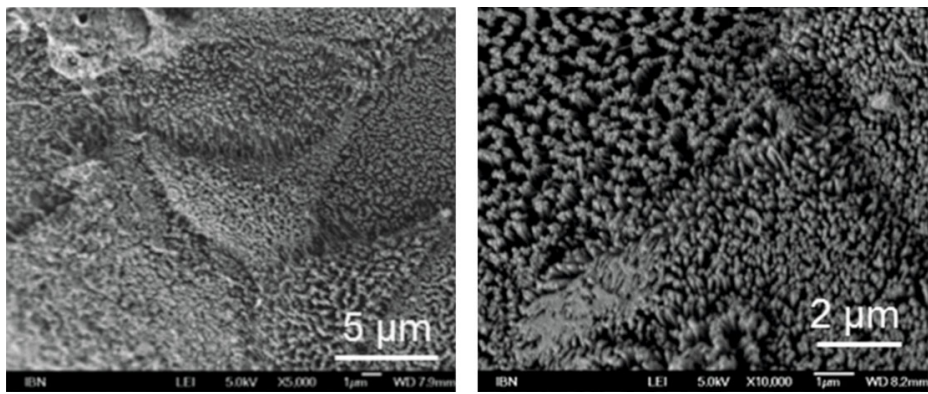

(c)
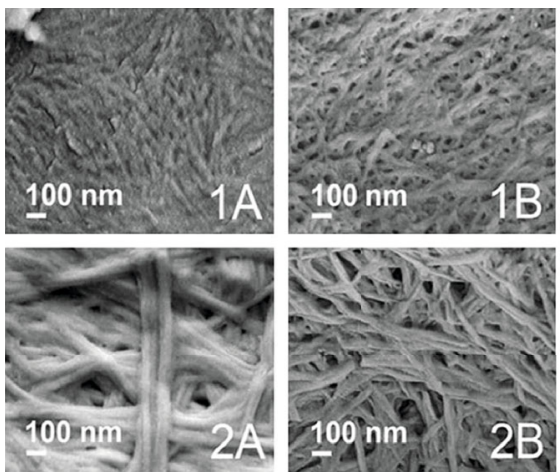

(d)
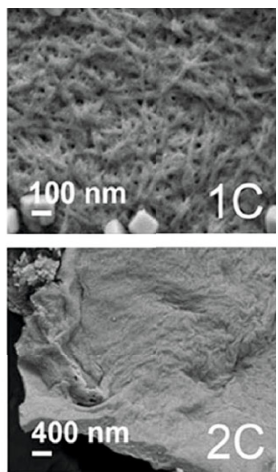

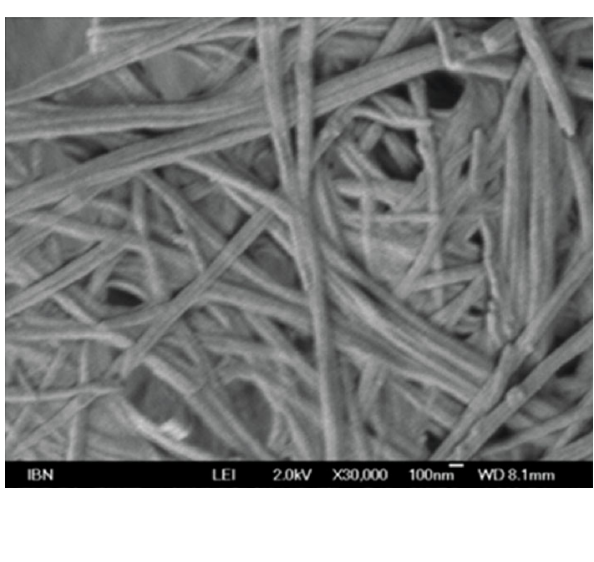

(b)

FIGURE 3: (a) Mechanism of assembly of aliphatic SAPs. Due to the hydrophobicity gradient in the peptide monomer, the monomers will assemble first in antiparallel pairs. Next, dimers will form intermediate $\alpha$-helical structures. The nanofiber will be formed when multimers stack into stable $\beta$-fibrils. (b) Field emission scanning microscopy (FESEM) of the interconnected nanofiber structures. (c) Field emission scanning microscopy (FESEM) of Caco2 intestinal epithelial cells cultured on an SAP hydrogel. Homogeneous microvilli phenotype can be observed. (d) Topography of trimers and pentamers with different C-terminus residues. The diameter and prevalence of the individual fibers depend on the properties of the changing residue. These figures have been reproduced with permission from the American Chemical Society and Springer Nature $[66,75]$.

among tissues with different physicochemical and mechanical requirements. These novel approaches concerning SAPs have given advances in the pragmatic use of state-of-the-art applications for these materials as a scaffold for TE, where a considerable quantity of biomaterial extracts from animals is needed. In addition to the characteristics of SAPs mentioned above, the study of these molecules helps to design a possible library of ultrashort peptides for diverse applications to understand complex actions in medicine, such as amyloid formation. For instance, the behavioral characterization of aliphatic peptides, resembling amyloid sequences, aids to the corroboration of the natural amyloid aggregation behavior corresponding to Alzheimer's and other degenerative diseases. The Hauser model proposes an aliphatic system to 
understand amyloidogenesis. Therefore, with this information, novel drugs and therapies could be developed to mitigate amyloid formation in the human body [76, 94]. The aliphatic ultrashort self-assembling peptides have been demonstrated to be suitable for a variety of interesting biomedical applications, including the use of peptide nanogels for wound healing applications in a burn wound model as well as in a full-thickness wound model $[95,96]$. Furthermore, a successful injectable therapy was demonstrated when using anticancer drug-loaded peptide hydrogels for the in vivo injection in breast tumors. A significant shrinking of the size of the tumor was observed in a mouse model [97]. Interestingly, amyloid-like peptide aliphatic hydrogels maintained the pluripotency state of human embryonic stem cells and human-induced pluripotent stem cells (iPSCs) during culturing in the peptide scaffold for over 9 months, so far the longest reported period of time to culture sensitive human embryonic stem cells in a synthetic matrix [67]. Microfluidic technologies allow to form peptide nanoparticles for drug delivery and for the use as theranostic agents $[98,99]$. Last, not least, bioimaging applications are feasible when referring to the interesting optical characteristics of these ultrashort aliphatic self-assembling peptides, making use of their nonlinear second harmonic behavior [100, 101].

A different type of SAPs is those developed by Insua and Montenegro [102]. The group proposes the use of cyclic peptides that assemble into nanotubes. Following, two exposed leucine and one tryptophan residue of the nanotubes bind and form nanosheet bilayers under acidic conditions. The remaining residues of the cyclic peptides are hydrophilic. This way, the nanosheet bilayer has a hydrophilic surface and several hydrophobic cores, suggesting potential applications as a molecular transporter and as stimuli-responsive membranes. On the other hand, Shi et al. [103] opted for the use of a phosphorylated 20-residue SAP to induce nanofiber assembly under the presence of phosphatase. In a dephosphorylated state, the SAPs fold into $\beta$-hairpin structures and stack into double layers due to the agglomeration of hydrophobic residues, resulting in a dry interface [104]. The new approach from the authors is aimed at phosphorylating the peptide in such a way that it would obstruct the generation of a hydrophobic pocket unless the residue becomes enzymatically dephosphorylated. This proves the versatility regarding nanostructures that can be achieved by the use of supramolecular peptide scaffolds.

Other approaches on peptide-derived SBPs include peptide-based assembling biomaterial with thixotropic behavior or, in other words, time-dependent shear-thinning hydrogels (Figure 4(a)) [105]. The peptides could potentially be used for active wound tissue regeneration as it maintains hydration and reduces bacterial contamination. The hydrogel is based on a construct of an Amoc (9-anthracenemethoxycarbonyl)-capped dipeptide; protected peptide-based hydrogelators show self-assembling behavior due to their hydrophobicity and aromaticity, which enhance interactions by $\pi-\pi$ stacking. The included phenylalanine side chains are thought to be useful for imitating the ECM, and they further aid the malleability of aggregating into different nanostructures. The hydrogel can be effectively used for wound healing applications due to its biocompatible cyclic oligosaccharides inherent to cyclodextrins, which have both a hydrophobic interior and a hydrophilic exterior that mimics the ECM. On the other hand, Zheng et al. designed a silk-based nanofiber that allowed scarless skin regeneration in functional tissue. In a microsphere conformation, the nanofiber imbues and disperses mesenchymal stem cells into an injectable hydrogel to simulate paracrine signaling and induce scarless skin regeneration with hair follicles (Figures 4(b) and 4(c)) [65]. The in vivo studies reveal an improvement and outstanding novelty compared to other traditional biomaterial systems, presenting a reliable TE method in the applications of nanofibers for wound healing. Both works prove that macromolecule-derived supramolecular biopolymers can be modified with unconventional functional groups or may contain full proteins and even so generate specific conformations due to the weak governing interactions.

Furthermore, Kong et al. carried out a study on the oral administration of peptide drugs, hampered by their metabolic instability and limited intestinal uptake. The synthesis of a peptide with gastrointestinal-protease-resistant behavior that counteracts the interleukin-23 receptor, which has a direct effect on ulcerative colitis and Crohn's disease formation, would be an interesting development of biomaterials for oral drug-delivery purposes. Orally administrated drugs are progressively degraded during intake. For this reason, low amounts of drugs generally arrive at the desired target. The authors designed an inhibiting peptide of coagulation factor XIa that is able to resist protease degradation in the gastrointestinal tract. In vivo tests showed that using bacteriophages that encode for the inhibiting double-bridge peptide, more than thirty percent of the peptide remained intact with small peptide traces within the blood of the mice [106].

2.2. Nucleic Acid-Derived Polymers. The interest in DNAand RNA-based scaffolds has been growing exponentially in the last decade. Similar to the origami technology, nucleotide-derived networks take advantage of the unique characteristics of nucleic acid polymers, i.e., pairing capability among complementary strands, sequence-dependent secondary structure, specific binding capability, controlled hybridization, and available DNA/RNA-interacting enzymes. Ever since the first DNA-containing hydrogels were reported in 1998 [107], which employed chemically modified salmon sperm DNA as a crosslinking agent in an acrylamide gel, nucleic acid-derived polymers have generated considerable interest as malleable natural biopolymers.

Novel strategies arose since the introduction of the first DNA crosslinked polyacrylamide (DNA-PA), like the switchable surface-integrated hydrogel from Kahn et al. [108]. The crosslinking mechanism is based on a hybridization chain reaction (HCR). Acrylamide chains were copolymerized with either DNA strand 1 or 3 . Strand 1 can hybridize into a hairpin loop, while strand 3 binds with the partially complementary DNA strand 2, and together, they hybridize into a single hairpin unit. Using a fourth DNA strand (4) that is complementary to the toehold region of strand 1 , the authors were able to develop a material that 


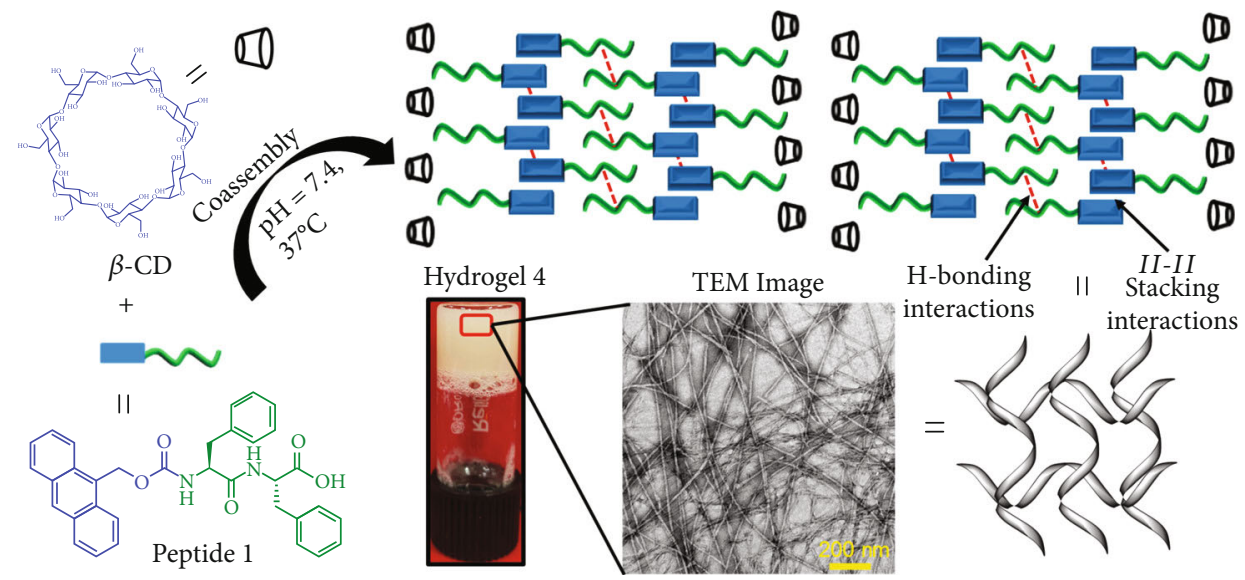

(a)

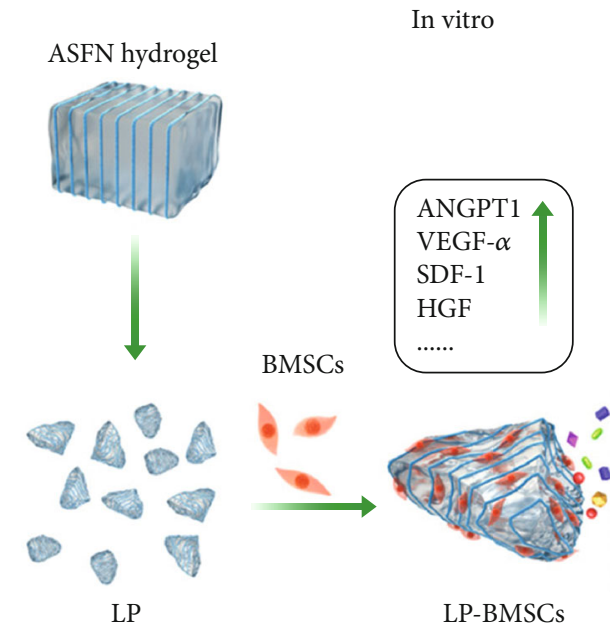

(b)

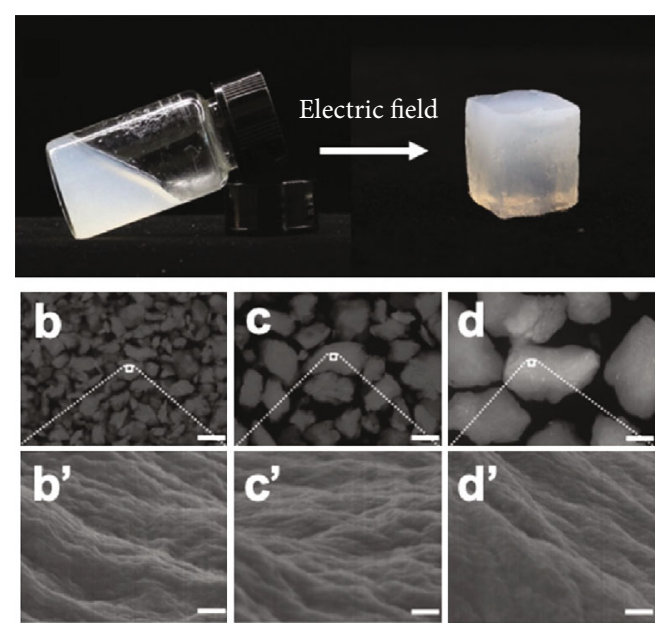

(c)

FIGURE 4: (a) Coassembly mechanism of thixotropic hydrogel. Nanofibers are a result of stacking and hydrogen bonding interactions among the residues of the monomer. The properties of the hydrogel are tuned with the use of $\beta$-cyclodextrin, in order to obstruct the assembly structure, which allows the hydrogel to be injectable. (b) A silk fibroin hydrogel was loaded with mesenchymal stem cells and growth factors that would allow cellular differentiation when bent in an in vivo model. (c) The hydrogel was separated with a molecular sieve, prepared under an electric field. The results show that the material retains a hierarchical, aligned structure. These figures have been reproduced with permission from the American Chemical Society and John Wiley and Sons [65, 105].

polymerizes into an Au-coated surface and simultaneously binds the two acrylamide polymers holding strand 1 or 3 . Therefore, strand 4 , which covers the surface, is used as an initiator for polymerization of an acrylamide gel. Additionally, the mechanical properties of the hydrogel can be enhanced more than 3-fold from 461 to $1770 \mathrm{~Pa}$ by adding potassium ions or 18-crown-6-ether to the system. The increase of the mechanical strength is caused by the formation and dissociation of G-quadruplexes of a fifth DNA strand copolymerized within both acrylamide chains. Although the research objective was the development of a hydrogel with on/off states for biosensing, the authors were able to design a sample material to be adapted into TE. Similar DNA-functionalized surfaces hold potential for skeletal TE where there is a demand for hard materials able to bond with soft hydrogels. The use of loop-hybridizing oligonucleotide systems for crosslinking initiation has ample applications for the crosslinking of polymers without the use or generation of cytotoxic compounds. Finally, this same system has an integrated "switch" system that signals into reversible stiffness changes which can be engineered into sensing specific cellular signals that require the release of either factors or cells, especially useful for the study of embryonic development.

DNA-derived polymers do not only serve as crosslinkers between copolymers, as is the case for DNA-acrylamide hydrogels, but can also create nanostructures or tridimensional networks among hybridized chains of DNA or RNA. These networks are not necessarily the main component of the hydrogel formulation, yet they contribute significantly to the mechanical or biological characteristics of the hydrogel. Um et al. generated branched DNA monomers able to assemble into variform DNA (namely, X, Y, and T) by ligase activity [109]. Originally planned for drug and cell release applications, this study showed the potential of nucleic acid-based hydrogels for the development of patient- 
specific grafts and personalized medicine, as well as genetic and stem cell therapies in a biomaterial that is by definition biocompatible and biodegradable.

Conde et al. [68] presented an improvement in DNAbased hydrogels by developing a self-assembly RNA-based hydrogel scaffold from microRNA modulation. By the time this study was published, the use of triple helices had not been employed for other purposes than protein regulation by nuclease or repressing activity. The authors could demonstrate the versatility of the secondary structure of nucleic acid polymers to form complex functional nanostructures. Two of the three oligonucleotide sequences were therapeutic and were able to form Watson-Crick and Hoogsteen hydrogen bonds among them. A third RNA strand would bind exclusively by Hoogsteen hydrogen bonds and stabilize the complex into a triple helix. The nanoparticles would form by complexing the triple helix with a poly(amidoamine) dendrimer solely by a difference in charges. The authors proved the cellular uptake of such scaffolds and the therapeutic RNA strands' effect as a tumor suppressor miRNA.

In 2008, Wang et al. [110] developed a two monomer DNA-containing hydrogel, in which one involved a threeoligomer, Y-shaped structure, and the second one was a linear dsDNA linker. The crucial characteristic feature is the sticky ends in both monomers, which allow crosslinking among the structure and the linker. The matrix proves to permit cellular migration that can be adjusted by the inclusion of signals within the hydrogel. Also, the crosslinking mechanism of the hydrogel allows adjacent macrostructures to fuse and heal. This characteristic behavior permitted the authors to generate DNA bricks to form more complex scarless structures that adhere effectively. A similar Y-shaped structure was used by Sato [111]. However, the linker was removed, so that the structure's sticky ends would be complementary. DNA droplets formed by nucleation and grew by collision and fusion. The droplets formed via liquid-liquid phase separation, allowing the macrostructures to aggregate selectively within themselves and to sequence specific Y-shaped structures depending on the DNA concentration. The authors developed a variety of specific sequences for the sticky ends of the structures, which would differ in their thermodynamic properties. The presence of a cross-bridging motif would favor the binding among the diverse sticky-end sequences; in addition to the degradation of the complex structures by RNases, this allows the creation of complex-shaped droplets. Although this project's scope seems to tackle a drug delivery matter, it could allow the development of regenerative medicine approaches, such as bioactive molecule encapsulation within cell-free tissue-engineered vascular drafts $[14,112]$.

Two recent publications describe the convergence of poly(ethylene glycol) diacrylate (PEGDA)/DNA hybrid hydrogels for a cell-free system, where a physically crosslinked DNA network-based cell fishing strategy is applied. As a result, an efficient capture was observed with $3 \mathrm{D}$ enveloping and enzyme-triggered release of bone marrow mesenchymal stem cells. The DNA network is generated by self-assembly via a second rolling circle amplification method and by assembly of two (number of lengths) DNA strands $[113,114]$ (Figure 5).
Qi et al. developed shape-controlled and self-assembled hydrogels using DNA sequences to control the shape of different hydrogels with self-assembling behaviors. They have reported about hydrogel cubes with edge lengths from 1 to $30 \mathrm{~nm}$. In a single reaction, 25 dimers were constructed in a high multiplex with 50 distinct hydrogel cube species. Since the cuboids display face-specific DNA glues, diverse structures are achieved in aqueous and interfacial agitation systems. Within aqueous systems, it was found that extended chains, network structures, squares, dimers, chains of fixed length, and $\mathrm{T}$-junctions could be generated in relation to the assembly systems. Therefore, this approach leads to a higher definition of hydrogel morphology at the nanoscale [115].

With regard to DNA-crosslinked polymers, Du and Hill [116] worked on a thorough characterization of DNApoly(acrylamide) PA hydrogels and their gelation kinetics. Using an $\mathrm{N}, \mathrm{N}^{\prime}$-methylene(bis)acrylamide as a chemical crosslinker, the group was able to identify the mechanistic role of both fragments and, hence, proposed and analyzed the longest relaxation times in correlation to the dissociation rates. Their model allowed the evaluation of interactions of other DNA-derived gel networks, such as the one presented by Anderson et al. [117]. In this case, "click" nucleic acids were conjugated to an eight-armed poly(ethylene glycol) PEG polymer through thiol-ene mechanisms, in order to overcome the scaling faults of fully formed DNA polymers. Crosslinking of the gel occurred by WatsonCrick base pairing and allowed reversibility at high temperatures (Figure 6). This work demonstrated the versatility of DNA-linked synthetic hydrogels, although their suitability in a biological setting was not evaluated.

In recent years, there has been a growing interest in the alternative application of the Clustered Regularly Interspaced Short Palindromic Repeats (CRISPR) technology, including its potential in stimuli-responsive materials. English et al. [118] used CRISPR-associated (Cas) enzymes and engineered DNA-based hydrogels to control the mechanical properties of the materials when specific sequences were detected by the enzymatic complex. The already known DNA-PA [108] can be crosslinked using an AT-rich oligonucleotide strand that binds to two noncomplementary strands in the DNA bridges. Using a highcatalytic-efficiency Cas 12 that cleaves AT-rich regions, the authors were able to induce and control the degree of bulk gel degradation by the concentration of trigger DNA. One of the most significant successes of the project is the capability of differentiation among oligonucleotide inputs, which cause individual responses in the hydrogel. Although the team successfully released both AuNPs and cells enclosed in the DNA-AP matrix, these experiments were solely a proof of concept for both TE and drug delivery assays. As the authors state, "this technology endorses the possibility of cargo release in tissue culturing after specific cellular cues." However, future work could include experiments to characterize the change of the mechanical properties as the DNA bridges are cleaved and foster the development of cellular factors detection systems, as well as the inclusion of several different oligonucleotides for stepped degradation of the artificial matrix. 


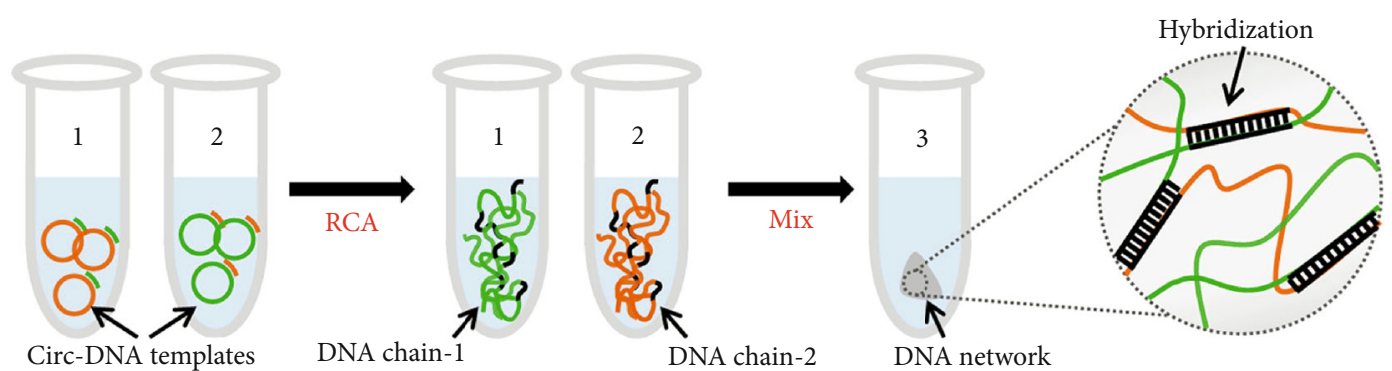

(a)

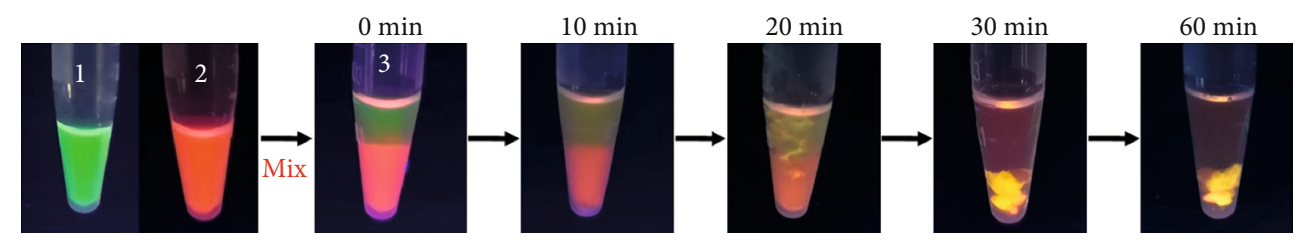

(b)

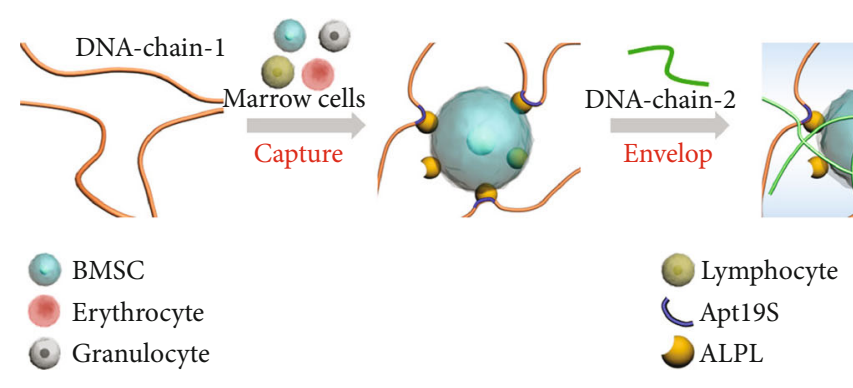

(c)

FIgURE 5: (a) It is possible to generate ultralong DNA chains using circular DNA templates. The strategy of elongation employed is a double rolling circle amplification (double RCA). Using two partially complementary DNA templates, the ultralong chains are able to hybridize with each other after mixing. (b) The use of stained DNA chains allows the observation of the hybridization process after being mixed. (c) The template DNA also contained aptamers that bind to a specific surface membrane protein (ALPL) of marrow cells. The authors designed a mechanism of capture and release of stem cells using the aptamer-containing ultralong DNA hydrogel and DNases for degradation of the matrix. These figures have been reproduced with permission from the American Chemical Society [114].

As specific DNA and RNA moieties bind to specific molecules, these materials can be used as low releasing systems, sensors, or inactivators. For further applications, Li et al. [119] present a comprehensive review of DNA hydrogels and microgels for other biological applications that differ from TE, such as biosensing. On the other hand, Chen et al. [120] cover a variety of strategies of DNA selfassembly for both the DNA-as-crosslinkers and DNA-aspolymer hydrogels.

2.3. Oligosaccharide-Derived Polymers. Native polysaccharides have complex architectures. They can be both homoand copolymers, linear or branched. Depending on the crosslinking mechanisms, polysaccharides can assemble into oriented fibers or tangled networks. The intricacy behind these biopolymers is related to their biosynthesis pathways and to their usually random copolymeric structure. Polysaccharides such as alginate, cellulose, and chitin have been repeatedly employed throughout the history of TE. However, saccharides in the ECM can also be found in the form of glycosaminoglycans and proteoglycans, enhancing the complexity behind the research and development of highly characterized saccharide-derived scaffolds.
The structural complexity of glycomolecules made it difficult to synthesize natural biopolymers based on saccharides. However, as proteoglycans and glycosaminoglycans are an essential part of the ECM to which they provide cellular signals, efforts to introduce specific oligosaccharides have been implemented in TE. Although these materials are not used as the main component for a scaffold, materials biofunctionalized with structurally defined oligosaccharides pose advantages over their naïve equivalent [121]. Moreover, oligosaccharides allow us to translate the various properties of polysaccharides into soluble, less viscous, or bioactive alternatives for their use in TE [122].

Hyaluronic acid, one of the most abundant proteoglycans in the mammalian ECM, has proven to modulate endothelialization in tissues by activating intracellular signaling cascades when present as low molecular weight oligomers [123]. This phenomenon is especially crucial for artificial vascularization when blood vessels align and attach to structures that work as the basement membrane. In a recent study, Kang et al. [124] reported that HA oligosaccharides (oHA) prevent coagulation and allow platelet adhesion. The oHA, ranging from tetra- to decamers, were immobilized in collagen by reductive amination and were used to generate 


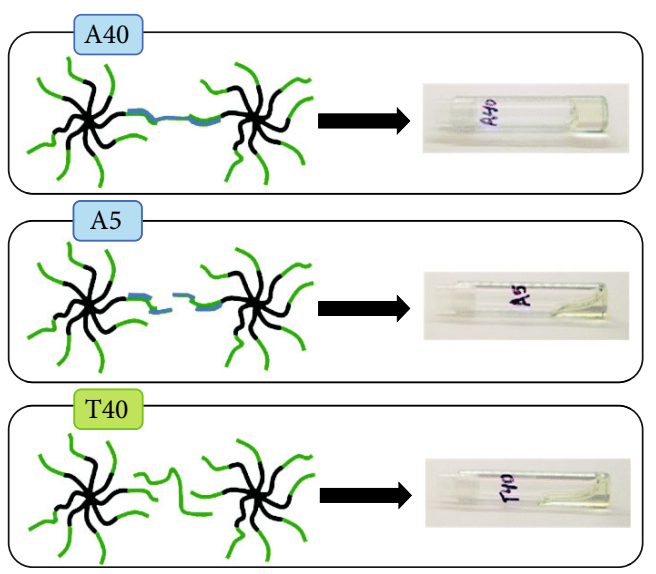

(a)

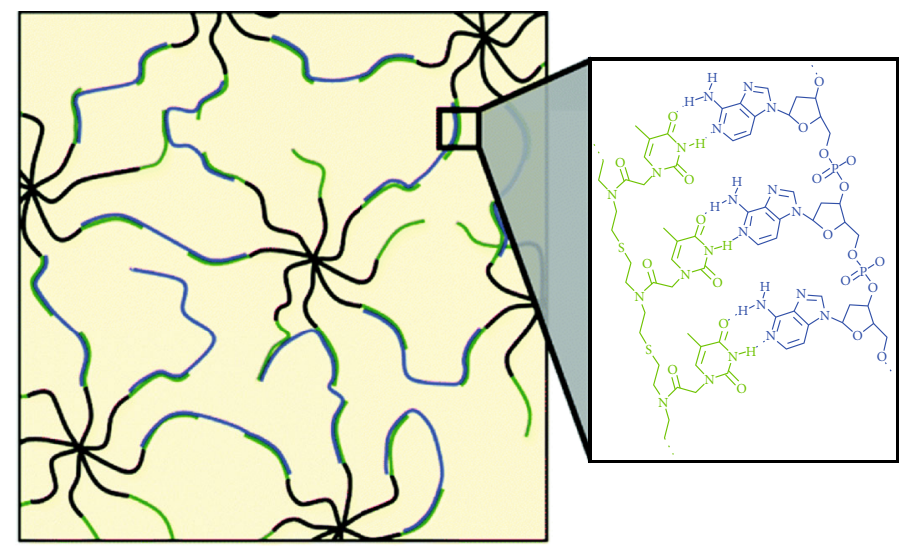

(c)

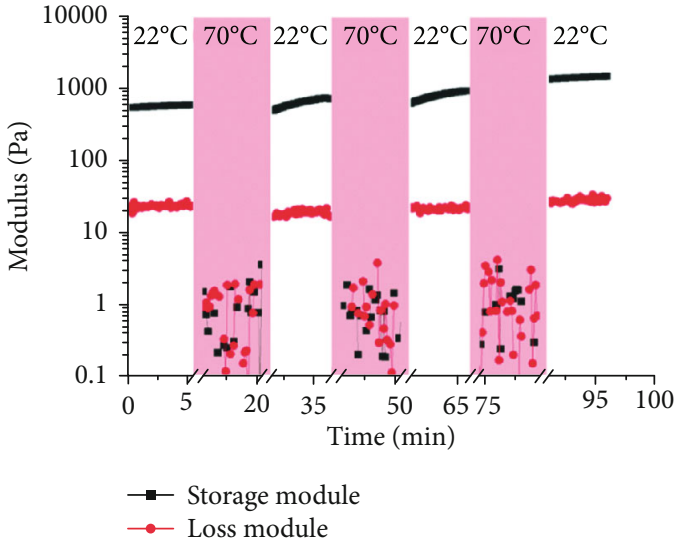

FIgURE 6: (a) Schematic of the "click" nucleic acids used for an 8PEG-thymine macromer crosslinking using a 40-mer adenine ssDNA, a 5mer ssDNA adenine, and a 40-mer thymine ssDNA. It was observed that the hydrogel would crosslink only in the presence of long thyminecomplementary strands. (b) When subjected to a denaturalizing temperature, the stiffness of the hydrogel decreased considerably. However, this mechanism appears to be reversible, as the mechanic properties of the material change accordingly to the input temperature. (c) As the 40-mer adenine ssDNA will anneal with the thymine strands, the crosslinker could potentially bind with multiple 8PEG-T oligomers. These figures have been reproduced with permission from the American Chemical Society [117].

electrospun nanofibers crosslinked by glutaraldehyde (GTA) vapor or 1-ethyl-3-[3-dimethylaminopropyl] carbodiimide hydrochloride (EDC). Endothelial cells seem to proliferate and migrate when embedded in an oHA-enriched collagen matrix. The same collagen/oHA matrices prepared by reductive amination have also been used in an independent study by $\mathrm{Li}$ et al. [125]. Due to the scaffold mineralization of hydroxyapatite, the group theorizes that oHA may enhance calcium chelation by providing new carboxyl groups (Figure 7). The presence of oHA improves the adhesion and proliferation of vascular cells while allowing osteoblast differentiation and infiltration in the nanofibers. It also proves the proficiency of collagen/oHA-based nanofibers as possible scaffolds for bone regeneration in the coming years. The inclusion of oHA in tissue scaffolds will allow the generation of bioactive matrices that may accelerate endothelialization which in turn may promote angiogenesis, a key component for the further study and development of the next generation of TE.

Similarly, chitosan oligomers, although naturally present in shells and outer skeletons of crustaceans, are known to modify the mammalian metabolic state and influence cell fate. Although not commonly employed within the principal composition of a scaffold for TE, its properties and manipulability show potential for both tissue regeneration and development of tissue grafts. Lv et al. [126] enriched a carboxymethyl chitosan/alginate hydrogel with chitosan oligosaccharide (COS), which affected the mechanical properties, gelling kinetics, and biological properties. A two-stage gelling process is observed under the coalescence of COS, when the carboxyl groups from carboxymethylcellulose (CMCS) and $\mathrm{COS}$ get protonated in a staggered manner. With respective pKa values of 6.5 and 5.8, electrostatic attractions are induced and the alginate matrix gets stabilized before the gelation 


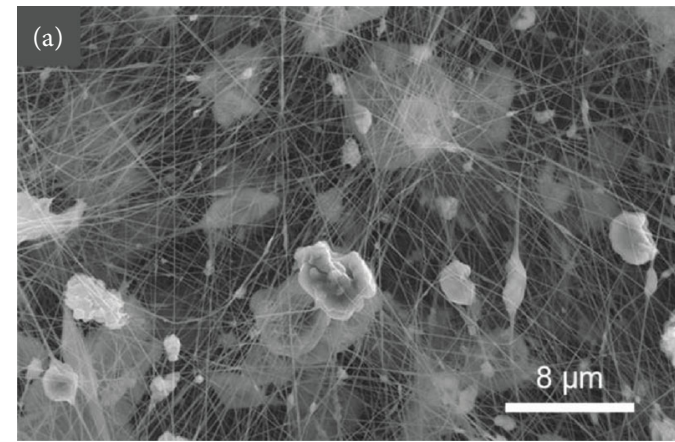

(a)

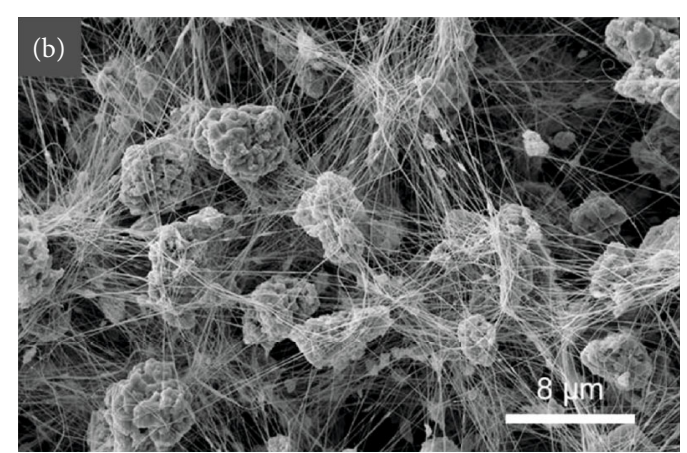

(b)

FIGURE 7: SEM images of electrospun nanofibers of (a) collagen/HA and (b) collagen/oHA. Inorganic particles mineralize within the nanofibers, promoted by the presence of oHA. The pattern of mineralization gave rise to a change in pore size which, in turn, enhances cell migration and proliferation within the voids. These figures have been reproduced with permission from Elsevier [125].

process is finalized. Low concentrations $(<0.5 \%)$ of COS showed prolonged viability of human umbilical cord mesenchymal stem cells and potential wound healing capabilities with no inflammation response and maturation of granulation tissue. Wound healing properties of chitosan have been addressed before by Sandri et al. [127]. A halloysite/COS nanocomposite was developed and tested as a wound dressing formulation for enhanced healing. COScontaining hydrogels seemed to enhance cell proliferation in vitro, whereas the use of the nanocomposite demonstrated the lowest lesion area $v s$. time profile when compared against the control groups. The histological analysis showed early reepithelialization and angiogenesis. COS has previously demonstrated anti-inflammatory activity by hampering the responses from lipopolysaccharides and inhibiting mitogen-activated protein kinase-dependent pathways [128, 129].

Oligosaccharide synthesis has historically been a laborintensive, inefficient, and time-consuming synthesis method. Rather than seen as synthesized products, oligosaccharides are usually degradation products of their polymeric form. The methods used for degradation of natural carbohydrates are hydrolysis, enzymatic or chemical cleavage, and radiation, where each of these procedures has different energetic, economical, and environmental costs. However, the resultant product is usually a mixture of oligosaccharides with varying molecular weights. We rarely obtain a final carbohydrate product of a structure-specific composition. The importance behind the automation of well-defined oligosaccharides relies on the capacity to characterize and study particular carbohydrate conformations and structure-property correlations within biological events [58, 59]. The development of an automated synthesis supports the opportunity to study and characterize the effects of biologically relevant complex saccharide motifs in the cellular environment and may be used in the creation of new smart and biofunctional scaffolds to achieve more complexity with a higher degree of biological simulation (biomimetics). The earlier mentioned efforts of Peter Seeberger and coworkers strengthen the goal of creating well-defined complex carbohydrate structures by applying automated glycan synthesis [130].

\section{SBPs for Tissue Engineering (TE)}

As it was stated by Williams [36], "the major problems of TE were apparent from the early experiences with skin.” Indeed, researchers worked hard to develop materials that replicate the nano- and microstructure of tissues, maintain their properties at physiological conditions, and are stable and biocompatible. However, TE is now reaching a new level of complexity: two-dimensional cell monolayers are moving to three-dimensional constructs (or even to four-dimensional ones) [131-133]. Cell lines are being replaced by pluripotent and patient-derived cells [134-136], and tissue grafts are evolving to organoids and whole organs [10, 16, 47, 136141]. As such, the materials employed must improve accordingly. By now, it is evident that SBPs have an opportunity to be widely used in TE applications; their particularities have the potential to solve current challenges that TE and regenerative medicine have brought upon material design. In Table 1, we can find a comprehensive overview regarding published approaches of SBPs for a specific application within TE.

We have briefly talked about the importance of induction of cellular responses by the scaffold, where cell fate is controlled by multiple chemical and physical cues from the cellular microenvironment. Signaling molecules are biochemical cues that promote adhesion, proliferation, migration, or differentiation. It is of indispensable interest for all TE approaches to control the presence and concentration of these signaling molecules in the cellular microenvironment. In a natural matrix, these factors can constrain the ability of cells to repair, regenerate, and replace tissue. This is why controlled delivery has become one of the fundamentals for tissue regeneration [142], where the induction of response is specifically relevant for the generation of organ-like structures.

Considering entrapped small signaling molecules, cyclodextrins (CDs) are good examples, because they are known for their host-guest complexation. CDs are able to entrap small molecules in the hydrophobic core by hydrophobic interactions. Current efforts to use CDs as delivery hydrogels are focusing on the development of derivatives of CDs for controlled delivery of small molecules [143]. For instance, 
TABLE 1: Engineered SBPs developed in the last 15 years arranged by applications on TE and regenerative medicine.

\begin{tabular}{|c|c|c|c|c|}
\hline Application & & Outcome & Biomolecule & $\begin{array}{l}\text { Possible main interacting } \\
\text { forces }\end{array}$ \\
\hline \multirow{9}{*}{$\begin{array}{l}\text { Complex macro- and } \\
\text { microstructures }\end{array}$} & & In situ multilayer bioprinting of DNA hydrogel [186] & $\mathrm{P}-\mathrm{N}$ & H-bonding \\
\hline & & Complex nanostructures (i.e., nanocircles) [187] & $\mathrm{N}$ & $\begin{array}{l}\text { H-bonding, hydrophobic } \\
\text { interactions }\end{array}$ \\
\hline & & Highly stable DNA fiber resistant to DNases [188] & $\mathrm{N}$ & $\begin{array}{l}\text { H-bonding, electrostatic } \\
\text { interactions }\end{array}$ \\
\hline & & DNA origami scaffold with lipid core [189] & $\mathrm{N}$ & $\begin{array}{l}\text { H-bonding, hydrophobic } \\
\text { interactions }\end{array}$ \\
\hline & & Vesicle forming DNA hydrogel [190] & $\mathrm{N}$ & $\begin{array}{l}\text { Electrostatic and } \\
\text { hydrophobic interactions }\end{array}$ \\
\hline & & Network scaffold from RNA [191] & $\mathrm{N}$ & H-bonding, $\pi-\pi$ stacking \\
\hline & & $\begin{array}{l}\text { Self-assembly peptides with fiber topology, } \\
\text { fine-tuning capacities [192] }\end{array}$ & $\mathrm{P}$ & $\begin{array}{l}\text { H-bonding, electrostatic } \\
\text { interactions }\end{array}$ \\
\hline & & DNA hydrogel bricks [110] & $\mathrm{N}$ & $\begin{array}{l}\text { H-bonding, electrostatic } \\
\text { interactions }\end{array}$ \\
\hline & & $\begin{array}{l}\text { DNA hydrogel modulated by internal } \\
\text { stress interactions [193] }\end{array}$ & $\mathrm{N}$ & H-bonding, ionic bridges \\
\hline \multirow{16}{*}{ Cellular scaffolds } & \multirow{8}{*}{$\begin{array}{l}\text { Tissue } \\
\text { microenvironment } \\
\text { development }\end{array}$} & $\begin{array}{l}\text { Peptide scaffold for gastrointestinal villi } \\
\text { reconstruction [67] }\end{array}$ & $\mathrm{P}$ & $\begin{array}{l}\pi-\pi \text { stacking, hydrophobic } \\
\text { interactions }\end{array}$ \\
\hline & & $\begin{array}{l}\text { Dentinogenic peptide hydrogel laden with } \\
\text { dental pulp stem cells [194] }\end{array}$ & $\mathrm{P}$ & $\begin{array}{l}\text { H-bonding, van der Waals } \\
\text { and electrostatic interactions }\end{array}$ \\
\hline & & $\begin{array}{l}\text { Osteogenic scaffold for the recapitulation } \\
\text { of nucleus pulposus phenotype [195] }\end{array}$ & $\mathrm{P}$ & $\begin{array}{l}\pi-\pi \text { stacking, hydrophobic } \\
\text { interactions }\end{array}$ \\
\hline & & $\begin{array}{l}\text { Osteogenic differentiation of human mesenchymal } \\
\text { stem cells in peptide scaffold [64] }\end{array}$ & $\mathrm{P}$ & Electrostatic interactions \\
\hline & & $\begin{array}{l}\text { Injectable alginate-peptide scaffold for } \\
\text { osteogenic differentiation [196] }\end{array}$ & $\mathrm{S}-\mathrm{P}$ & $\begin{array}{l}\pi-\pi \text { stacking, hydrophobic } \\
\text { interactions }\end{array}$ \\
\hline & & $\begin{array}{l}\text { Peptide scaffold that promotes epithelial } \\
\text { regeneration [197] }\end{array}$ & $\mathrm{P}$ & $\begin{array}{l}\text { Hydrophobic interactions, } \\
\text { H-bonding }\end{array}$ \\
\hline & & $\begin{array}{l}\text { Scaffold for mesenchymal stem cell-derived } \\
\text { extracellular vesicles release for tissue repair [62] }\end{array}$ & $\mathrm{P}$ & $\begin{array}{l}\pi-\pi \text { stacking, hydrophobic } \\
\text { interactions }\end{array}$ \\
\hline & & $\begin{array}{l}\text { Peptide scaffold for oesophageal epithelial } \\
\text { and fibroblast coculturing [63] }\end{array}$ & $\mathrm{P}$ & $\begin{array}{l}\pi-\pi \text { stacking, hydrophobic } \\
\text { interactions }\end{array}$ \\
\hline & \multirow[t]{7}{*}{ Bioactive } & $\begin{array}{l}\text { Peptide scaffold that promotes vascularization } \\
\text { and innervation innately [198] }\end{array}$ & $\mathrm{P}$ & Hydrophobic interactions \\
\hline & & $\begin{array}{c}\text { Peptide scaffold for proliferation and migration } \\
\text { of human umbilical endothelial cells by localized and } \\
\text { controlled release of } \mathrm{H}_{2} \mathrm{~S}[60]\end{array}$ & $\mathrm{P}$ & Electrostatic interactions \\
\hline & & 3D peptide scaffold for neuron proliferation [199] & $\mathrm{P}$ & $\begin{array}{l}\text { H-bonding, hydrophobic } \\
\text { interactions }\end{array}$ \\
\hline & & $\begin{array}{c}\text { Peptide-carbon nanotube complex that promotes } \\
\text { natural cell behavior and affects cancer cell } \\
\text { microenvironment }[200]\end{array}$ & $\mathrm{P}$ & $\begin{array}{l}\text { Hydrophobic, electrostatic, } \\
\text { van der Waals interactions }\end{array}$ \\
\hline & & $\begin{array}{l}\text { Injectable peptide for oligodendrocyte } \\
\text { encapsulation and proliferation [201] }\end{array}$ & $\mathrm{P}$ & $\begin{array}{l}\text { Hydrophobic interactions, } \\
\qquad \pi-\pi \text { stacking }\end{array}$ \\
\hline & & $\begin{array}{l}\text { Injectable hydrogel with slow degradation that } \\
\text { allows the regeneration of native ECM [184] }\end{array}$ & P-S & Electrostatic interactions \\
\hline & & $\begin{array}{l}\text { DOX-releasing system that also promotes } \\
\text { dendritic cell maturation [202] }\end{array}$ & $\mathrm{P}$ & $\begin{array}{l}\text { H-bonding, electrostatic } \\
\text { interactions }\end{array}$ \\
\hline & Stem cell culturing & $\begin{array}{l}\text { Injectable peptide scaffold for embryonic } \\
\text { stem cell culture [203] }\end{array}$ & $\mathrm{P}$ & $\begin{array}{l}\pi-\pi \text { stacking, hydrophobic } \\
\text { interactions }\end{array}$ \\
\hline
\end{tabular}


TABLE 1: Continued.

\begin{tabular}{|c|c|c|c|c|}
\hline Application & & Outcome & Biomolecule & $\begin{array}{l}\text { Possible main interacting } \\
\text { forces }\end{array}$ \\
\hline \multirow{11}{*}{ Smart scaffolds } & Stimuli responsive & pH-responsive DNA hydrogel [204] & $\mathrm{N}$ & Triple H-bonding \\
\hline & & pH-responsive cyclic DNA scaffold [205] & $\mathrm{N}$ & H-bonding \\
\hline & & $\begin{array}{l}\text { pH-responsive alginate hydrogel functionalized } \\
\text { with hyaluronan oligosaccharides [206] }\end{array}$ & $S$ & H-bonding \\
\hline & & Glucose-responsive, insulin release system [207] & $\mathrm{P}$ & $\begin{array}{l}\text { H-bond, hydrophobic } \\
\text { interactions }\end{array}$ \\
\hline & & ATP-responsive DNA hydrogel [208] & $\mathrm{N}$ & H-bonding \\
\hline & & $\begin{array}{l}\text { Enzyme-responsive, silica-coated with konjac } \\
\text { oligosaccharide [209] }\end{array}$ & $S$ & H-bonding, $\pi-\pi$ stacking \\
\hline & & $\begin{array}{l}\text { Nanotube-DNA hydrogel optothermally } \\
\text { responsive [210] }\end{array}$ & $\mathrm{N}$ & H-bonding \\
\hline & & $\begin{array}{c}\text { MicroRNA responsive, DNA hydrogel for cancer } \\
\text { screening [211] }\end{array}$ & $\mathrm{N}$ & H-bonding \\
\hline & & $\begin{array}{c}\text { Thermoresponsive beta-cyclodextrin-based } \\
\text { hydrogel }[212,213]\end{array}$ & S & $\begin{array}{l}\text { H-bonding, hydrophobic } \\
\text { interactions }\end{array}$ \\
\hline & & Light-induced release, DNA hydrogel [214] & $\mathrm{N}$ & H-bonding, $\pi-\pi$ stacking \\
\hline & Shape memory & $\begin{array}{l}\text { Reversible, CMC-based driven by chemical } \\
\text { and physical stimuli [215] }\end{array}$ & S & Donor-acceptor interactions \\
\hline \multirow{9}{*}{ Delivery } & Drug & $\begin{array}{l}\text { Chitosan oligosaccharide drug delivery vehicle } \\
\text { with enhanced membrane permeability [216] }\end{array}$ & S & Not detailed \\
\hline & & DNA nanosponges for drug delivery [217] & $\mathrm{N}$ & Electrostatic interactions \\
\hline & & DNA-PA hydrogel for controlled release [218] & $\mathrm{N}$ & $\begin{array}{l}\text { Hydrophobic interaction, } \\
\text { H-bonding }\end{array}$ \\
\hline & Cell & Injectable peptide scaffold for cell delivery [219] & $\mathrm{P}$ & $\begin{array}{l}\text { H-bonding, electrostatic } \\
\text { interactions }\end{array}$ \\
\hline & Enzyme & Water-insoluble peptide for enzyme protection [220] & $\mathrm{P}$ & H-bonding, $\pi-\pi$ stacking \\
\hline & Genetic material & Hydrogel for sustained RNA release [221] & $\mathrm{N}$ & H-bonding \\
\hline & & $\begin{array}{l}\text { Chitosan-graft-(PEI- } \beta \text {-cyclodextrin) copolymers } \\
\text { for DNA and siRNA delivery [222] }\end{array}$ & S & $\begin{array}{l}\text { H-bonding, electrostatic } \\
\text { interactions }\end{array}$ \\
\hline & & Cell-penetrating peptide for gene delivery [223] & $\mathrm{P}$ & Electrostatic interactions \\
\hline & & DNA hydrogel for nucleic acid delivery [224] & $\mathrm{N}$ & H-bonding, $\pi$ - $\pi$ stacking \\
\hline \multirow{6}{*}{ Therapeutic } & & $\begin{array}{l}\text { Adhesive DNA hydrogel with antimicrobial } \\
\text { properties }[61,225]\end{array}$ & $\mathrm{N}$ & H-bonding \\
\hline & Wound regeneration & Hydrogel for accelerated healing [185] & $\mathrm{P}$ & Hydrophobic interactions \\
\hline & & $\begin{array}{l}\text { Hydrogel with hyaluronan oligosaccharides } \\
\text { for accelerated diabetic wound healing [206] }\end{array}$ & $S$ & Not detailed \\
\hline & Immobilization & $\begin{array}{l}\text { Microsurgery assistance-hydrogel for the } \\
\text { immobilization of ultrasmall vessels. [226] }\end{array}$ & $\mathrm{P}$ & $\pi-\pi$ stacking \\
\hline & Cancer therapy & $\begin{array}{l}\text { Hexapod-like DNA hydrogel for photothermal } \\
\text { immunotherapy [227] }\end{array}$ & $\mathrm{N}$ & Not detailed \\
\hline & Immunotherapy & $\begin{array}{l}\text { DNA hydrogel as a vaccine system by } \\
\text { noncovalent binding [228] }\end{array}$ & $\mathrm{N}$ & Electrostatic interactions \\
\hline
\end{tabular}

$\mathrm{N}=$ nucleic acid-based material; $\mathrm{S}=$ oligosaccharide-based material; $\mathrm{P}$ = peptide-based material.

Fiorica et al. developed a hyaluronic acid/CD hydrogel for injectable localized chemotherapy [144]. The authors reported a remarkable release period of over 1 month, due to $\mathrm{CD}$ complexation. Furthermore, when performing in vivo tests, they observed a reduction on the solid tumor volume and no damage to other tissues due to the presence of the cytotoxic chemotherapy agent. Another creative approach to the use of CDs was reported in 2019 [145]. Here, the use of poly-CDs as a crosslinking agent in a solution of a tetronic-adamantane conjugate generated a shear-thinning, micelle-based hydrogel by simple mixing. Furthermore, chemotherapy drugs were loaded and successfully delivered to cellular environments at a low $\mathrm{pH}(<7.4 \mathrm{pH})$. Furthermore, besides their long-proved capability to deliver chemotherapy drugs, CD-based hydrogels have proven to be useful gene delivery agents [146]. If coupled with other small molecules, CDs may work as delivery vehicles of small signals to induce specific cell responses.

On another hand, self-assembling peptide hydrogels can also work as injectable scaffolds for controlled delivery of 
small molecules. Oxaliplatin-derived peptide hydrogels showed significant growth inhibition of breast tumors in a mouse breast cancer model. Before injecting the therapeutic hydrogel for the localized therapy, the peptide hydrogel was functionalized by ligating the anticancer drug oxaliplatin via click chemistry [97]. In a very comprehensive review, Wang et al. recollect a variety of strategies to design and implement peptides for drug delivery [147]. One of the most novel efforts on peptides for drug delivery is the D3F3 forky peptide designed by Tao et al. [148]. The resultant fibers of the peptide self-assembly are able to bind to doxorubicin (DOX), a known chemotherapy drug. However, once the zinc ion concentration overcomes a threshold, the fibers will form a gel among themselves and release DOX. This mechanism was thought for controlled delivery of DOX into the prostate, where the concentration of zinc ions is significantly higher than in the bloodstream.

By definition, origami DNA is an SBP. We can easily figure out why this complex 3D structure can be used as smart delivery vehicles. Complex 3D DNA structures are evidently easier to design and synthesize which make them a versatile drug delivery tool $[149,150]$. A current DNA origami drug delivery approach consisted in a bundle of nanostructures that would carry and release DOX after the detection of signal molecules by the cell and the following endocytosis of the delivery bundle. This novel approach serves as proof of concept of a stable and specific ligand-drug conjugate facilitated by a DNA origami scaffold [151].

The controlled delivery of small molecules has important implications for TE. To be more specific, we will briefly talk about vascularization, which is needed to irrigate thick constructs, as diffusion is not optimal for mass transfer over large distances $(>200 \mu \mathrm{m})[152,153]$. Vascularization is a process mainly dependent on cell-ECM interactions [154-157]. One of the current approaches to solve this issue was the synthesis of a self-assembling glycosylated peptide used to mimic the highly glycosylated environment of the ECM. Coupled with a proangiogenic factor, the peptide was able to induce microvascularization in vivo and in vitro [158]. Another interesting approach is shown by an injectable gelatin hydrogel modified with a cyclodextrin motif that would entrap antioxidative molecules. The inclusion of such molecules enabled the enhanced angiogenesis in vivo [159]. For a more profound description of the state-of-the-art and the role of materials in angiogenesis, we recommend the review of Lee et al. [160].

Besides small molecule delivery, complex tissue development also encompasses the fabrication of complex microstructures that are anatomically relevant. Most complex organs, such as the lungs, kidneys, and glands, are formed by several branched, independent, organized cellular aggregates. In order to reproduce organ-specific microstructures, biomaterials should be versatile enough to allow the growth and self-organization of several cellular subtypes [46, 161163]. This implies the following matrix rearrangement according to the stochastic cell growth. Self-healing SBPs form dynamic scaffolds that allow a constant ECM remodeling according to the cellular movement. A recent review on self-healing hydrogels describes several approaches using cyclodextrins and peptides [164]. Peptides have been largely explored as self-healing scaffolds [165]. A series of injectable dipeptides have shown instantaneous self-healing properties, while presenting a wide range of tunable mechanical properties. In vivo experiments demonstrated that this material, when used as a filler, exhibits low inflammatory responses [166].

\section{Supramolecular Biopolymers for Bioprinting}

Recently, additive manufacturing protocols have been optimized for diverse biofabrication needs, depending on the material's requirements and their desired morphology [167]. The design of a meaningful material is the initial crucial step for establishing a suitable scaffold in order to accommodate specific kinds of cells or tissue. Each material has limitations regarding its use for experimental and translational applications. In an effort to overcome the inherent limitations of bioinks, such as weak mechanic properties or low printing resolution, researchers have developed data processing strategies to achieve high-resolution structures $[168,169]$. Currently, there is a demand for customized bioinks, as well as for hardware and software. Various emergent startup companies, such as Allevi, Cellink, and Organovo, besides many others, have developed suitable bioinks for bioprinting in combination with corresponding printing equipment. Still, the use of existing bioprinting protocols remains a constant challenge, due to the unforeseen behavior and limitations when combining biomaterials, chemical constituents, growth factors, and cells [170]. The review of Mir et al. is recommended for deeper understanding of the overall potential of bioprinting [171].

To overcome these limitations, different techniques like material extrusion [172, 173], material jetting [174-176], and vat polymerization [177, 178] (which encompasses stereolithography and two-photon polymerization) [179] were introduced. In addition, novel innovative methods have been developed such as, for instance, computed axial lithography, better known as volumetric printing, with the aim to print photocrosslinkable polymers faster and with better resolution [180]. Furthermore, recently, the use of state-ofthe-art robotics for bioprinting has started. By having different-degree-of-freedom robotic arms, the robots can mimic fine human movements -in an effort to simulate human surgeons-while providing the accuracy of machines. The robots are directly used for the bioprinting of gel material, where all the detailed programming for incorporation of cells, extrusion of material, and pressure and/or velocity settings are included [66].

Additionally, as printing fidelity and reproducibility of biomaterials is required for superior performances, the use of rationally designed ad hoc synthetic SBPs has a clear advantage over other bioinks. This allows achieving higher accuracy in vitro, ex vivo, and in vivo, which is fundamental for punctual applications. To give an example, Muller et al. used biomaterials with solid fractions, such as bioceramics or nanoparticles for bone or cartilage tissue regeneration. Because of the presence of two different materials, the particles and the hydrogel produce inconsistent dispersion of 
particles; thus, the printing or the formation of the desired morphology is difficult to achieve. The group solved this issue by the use of gellan gum methacrylate, hyaluronic acid methacrylate with hydroxyapatite crystals or particles that enhanced the ink's printability. Cryomilling of the ink components decreased its viscosity 10 -fold with a shear rate of $0.1 \mathrm{~s}^{-1}$ without compromising homogeneity and stronger interlayer adhesion between layers [181]. In another study from the same group, the designed bioink showed a mechanical improvement after dynamic covalent links between the amine and $45 \mathrm{~nm}$ sized silica nanoparticles that were imbued in state-of-the-art oxidized alginate. The reversible imine bonds between amines on the nanoparticles and aldehydes of oxidized alginate lead to significant enhancement of the rheological properties and better printability. The yield stress increased 5.4-fold without compromising the biocompatibility of the bioink when using $2 \mathrm{wt} \%$ nanoparticles [182].

Moreover, as stated before, it is preferable to avoid the use of cytotoxic crosslinkers or UV light, which can be damaging to the cells. Indeed, SBPs assembly can be triggered by different stimuli, e.g., ions, and this capability is also exploited in bioprinting. For instance, Kim and coworkers [183] designed a self-assembling saccharide-based bioink, based on competitive covalent bonding between hyaluronate and a watersoluble form of chitosan, with self-healing capability. Using acid dihydrazide, the hyaluronate and glycol chitosan forms acylhydrozane bonds. Moreover, changing the molecular weight of the hyaluronate allowed the material to change its mechanical properties and to be extruded without a postgelation system. However, neither conformational-specific oligosaccharides nor nucleic acid-derived hydrogels have been yet explored as bioinks: we expect SBP hydrogels to be used as smart and bioactive materials for bioprinting soon.

\section{Conclusions and Outlook}

SBPs are polymeric units that self-assemble to supramolecular scaffolds by noncovalent interactions. Because of their unique properties, they appear as promising alternatives that are able to overcome existing challenges in TE. Currently, there is a lack of robust materials that can be appropriately used for the development of organoids, whole-organ engineering, patient-specific tissue regeneration, or in situ therapeutics. Using interactive motifs, SBPs can be easily functionalized into bioactive materials. SBPs are also often thermodynamically reversible, which supports self-healing properties. Furthermore, these materials can include stimuli-responsive motifs.

Peptide- and nucleic acid-derived polymers have resolved a variety of issues that saccharide-derived supramolecular biopolymers did not yet resolve, such as routine procedures for characterization and elucidation of binding and annealing mechanisms. Chemically synthesized macromolecular biopolymers have the advantage of not to depend on batch-to-batch variations which can cause serious troubles when using natural-derived biopolymers. It is recommended to think about the possible implementation of SBPs in situ and engineer additional traits that may enhance its properties. For example, it would be suggested to work on nature-inspired self-assembly peptides for the generation of detection probes. A second example would be to step on the conjugation of optically active molecules to allow the detection of specific molecular phenomena, such as selfhealing or annealing. Further studies could also focus on the generation of matrices with gradients of density to allow specific geographical mechanical stimuli.

Currently, a major challenge is the lack of smart synthesis methods for complex oligosaccharide structures. There is obviously a need to develop methods that will allow the generation of branched oligosaccharides. Methods to be explored include the use of glycosylases within an automated chemical polymerization. The development of novel synthesis strategies will support the generation of complex and well-characterized materials such as glycopeptides or nucleic acid/saccharide-based hydrogels. This will also give additional opportunities for the inclusion of specific signaling oligosaccharides within a matrix and will amplify the spectrum of bulk properties of the novel scaffolds and their overall tunability. Particularly regarding sugars, the development of a high-yield synthesis will unleash the potential of using saccharides with a specific confirmation as part of a scaffold that would mimic the presence of glycosaminoglycans and even proteoglycans found in the extracellular matrix. In addition, given that a high percentage of membrane proteins respond to glycosylated molecules, it is important to focus on the effect of sequence-specific oligosaccharides in order to enhance the cell-ECM interactions in materials.

Moreover, smart novel materials offer a variety of biochemical cues and physicochemical properties useful for the development of specific materials for TE. Some of these materials have already been studied under in vivo conditions, such as the self-healing peptide-based hydrogel from Tondera et al. [184], which did not trigger any inflammatory response when injected in mice, or a peptide-based wound dressing developed by our group [185] which not only presumably suppressed inflammatory reactions but also allowed accelerated wound healing. This suggests that the development of designer supramolecular biopolymers composed of peptides and nucleic acids may bring us closer to optimized healthcare technologies. Under these premises, it is important to promote the translation of promising SBPs into medical devices for detection of molecules, high-end and cell-free prosthesis, or topical treatments. This will certainly facilitate future applications of cell-laden or smart drug delivery TE devices based on SBPs. Another alternative will be the study of bioactive SBP scaffolds for cell-free therapies.

SBPs offer a robust and tunable platform for the creation of personalized materials for TE. However, at this moment, the design is limited to experts in polymer biochemistry. Only the design of DNA origami structures has the potential to allow nonexperts to make use of them. Therefore, future projects could also focus on the development of information technology (IT) tools to facilitate the in silico design of SBPs. The generation of such tools would enhance the accessibility of such materials.

Supramolecular biopolymers made from biomolecules hold several advantages over natural biopolymers or synthetic biopolymers, because they give a multitude of 
structural diversity by applying rational design and combinatorial approaches. Peptide- and nucleic acid-based materials are employed for TE applications as they are relatively easy to tune due to their sequence-dependent characteristics, such as annealing time, conductivity, hydrophobicity, porosity, binding capacity, stimuli-responsiveness, and biocompatibility. Although the more complex oligosaccharide synthesis is lagging behind peptide and nucleic acid synthesis, current promising new efforts will allow the design and study of more complex oligosaccharide-based materials for TE in the same manner. Currently, designer supramolecular biopolymers are proving their efficacy as cellular scaffolds and versatile modulators of the cellular microenvironment. Further efforts for the inclusion of these materials into advanced TE and healthcare applications are expected in the years to come.

\section{Abbreviations}

SBP: Supramolecular biopolymer

SPS: Solid phase synthesis

TE: Tissue engineering

SAP: Self-assembling peptide.

\section{Conflicts of Interest}

The authors declare no conflict of interest for this paper.

\section{Authors' Contributions}

M.P.P. and A.A.R. contributed equally to the final manuscript; M.M. and Z.K. assisted with a critical revision of the article; C.A.E.H. advised on the content of the manuscript and corrected and approved the final version for publishing.

\section{Acknowledgments}

Graphical abstract was created with http://biorender.com/. Funding was provided by KAUST under baseline funds, BAS/1/1075-01-01.

\section{References}

[1] L. Wang, C. Gong, X. Yuan, and G. Wei, "Controlling the self-assembly of biomolecules into functional nanomaterials through internal interactions and external stimulations: a review," Nanomaterials, vol. 9, no. 2, 2019.

[2] C. A. Hauser and S. Zhang, "Designer self-assembling peptide nanofiber biological materials," Chemical Society Reviews, vol. 39, no. 8, pp. 2780-2790, 2010.

[3] R. Otter and P. Besenius, "Supramolecular assembly of functional peptide-polymer conjugates," Organic \& Biomolecular Chemistry, vol. 17, no. 28, pp. 6719-6734, 2019.

[4] W. S. Marshall and R. J. Kaiser, "Recent advances in the highspeed solid phase synthesis of RNA," Current Opinion in Chemical Biology, vol. 8, no. 3, pp. 222-229, 2004.

[5] M. Dhanawat and S. K. Shrivastava, "Solid-phase synthesis of oligosaccharide drugs: a review," Mini Reviews in Medicinal Chemistry, vol. 9, no. 2, pp. 169-185, 2009.

[6] V. Mäde, S. Els-Heindl, and A. G. Beck-Sickinger, "Automated solid-phase peptide synthesis to obtain therapeutic peptides," Beilstein Journal of Organic Chemistry, vol. 10, pp. 1197-1212, 2014.

[7] P. Chandika, S.-Y. Heo, T.-H. Kim et al., "Recent advances in biological macromolecule based tissue-engineered composite scaffolds for cardiac tissue regeneration applications," International Journal of Biological Macromolecules, vol. 164, pp. 2329-2357, 2020.

[8] R. Marmorstein and M. X. Fitzgerald, "Modulation of DNAbinding domains for sequence-specific DNA recognition," Gene, vol. 304, pp. 1-12, 2003.

[9] R. L. Robert Lanza, J. Vacanti, A. Anthony, R. L. Robert Lanza, J. Vacanti, and A. Atala, Principles of Tissue Engineering, Elsevier, 5th edition, 2020.

[10] S. Sohn, M. V. Buskirk, M. J. Buckenmeyer, R. Londono, and D. Faulk, "Whole organ engineering: approaches, challenges, and future directions," Applied Sciences, vol. 10, no. 12, p. $4277,2020$.

[11] K. Uday Chandrika, R. Tripathi, Y. Kameshwari, N. Rangaraj, J. Mahesh Kumar, and S. Singh, "Refunctionalization of decellularized organ scaffold of pancreas by recellularization: whole organ regeneration into functional pancreas," Tissue Engineering and Regenerative Medicine, 2020.

[12] S. E. Park, A. Georgescu, and D. Huh, "Organoids-on-achip,” Science, vol. 364, no. 6444, pp. 960-965, 2019.

[13] I. Fernández-Cervantes, N. Rodríguez-Fuentes, L. V. LeónDeniz et al., "Cell-free scaffold from jellyfish Cassiopea andromeda (Cnidaria; Scyphozoa) for skin tissue engineering," Materials Science and Engineering: C, vol. 111, p. 110748, 2020.

[14] Z. Wang, C. Liu, Y. Xiao et al., "Remodeling of a cell-free vascular graft with nanolamellar intima into a neovessel," ACS Nano, vol. 13, no. 9, pp. 10576-10586, 2019.

[15] H. Kwan, E. Chisari, and W. S. Khan, "Cell-free scaffolds as a monotherapy for focal chondral knee defects," Materials, vol. 13, no. 2, p. 306, 2020.

[16] S. Hedayat and N. Valeri, "Patient-derived organoids: promises, hurdles and potential clinical applications," Clinical Oncology, vol. 32, no. 4, pp. 213-216, 2020.

[17] H. Zhang, T. Fan, W. Chen, Y. Li, and B. Wang, "Recent advances of two-dimensional materials in smart drug delivery nano-systems," Bioactive Materials, vol. 5, no. 4, pp. 1071-1086, 2020.

[18] M. Shahriari, V. P. Torchilin, S. M. Taghdisi, K. Abnous, M. Ramezani, and M. Alibolandi, “"Smart” self-assembled structures: toward intelligent dual responsive drug delivery systems," Biomaterials Science, vol. 8, no. 21, pp. 5787$5803,2020$.

[19] J. L. Beesley and D. N. Woolfson, "The de novo design of $\alpha$ helical peptides for supramolecular self-assembly," Current Opinion in Biotechnology, vol. 58, pp. 175-182, 2019.

[20] K. Ariga, M. Nishikawa, T. Mori, J. Takeya, L. K. Shrestha, and J. P. Hill, "Self-assembly as a key player for materials nanoarchitectonics," Science and Technology of Advanced Materials, vol. 20, no. 1, pp. 51-95, 2019.

[21] W. Zhang, X. Yu, Y. Li, Z. Su, K. D. Jandt, and G. Wei, "Protein-mimetic peptide nanofibers: motif design, selfassembly synthesis, and sequence-specific biomedical applications," Progress in Polymer Science, vol. 80, pp. 94-124, 2018.

[22] Z. Su, R. Zhang, X.-Y. Yan et al., "The role of architectural engineering in macromolecular self-assemblies via non- 
covalent interactions: a molecular LEGO approach," Progress in Polymer Science, vol. 103, p. 101230, 2020.

[23] B. O. Okesola, C. Redondo-Gómez, and A. Mata, "18- Multicomponent self-assembly: supramolecular design of complex hydrogels for biomedical applications," in Self-assembling Biomaterials, H. S. Azevedo and R. M. P. Silva, Eds., pp. 371-397, Woodhead Publishing, 2018.

[24] D. J. Pochan, J. P. Schneider, J. Kretsinger, B. Ozbas, K. Rajagopal, and L. Haines, "Thermally reversible hydrogels via intramolecular folding and consequent selfassembly of a de novo designed peptide," Journal of the American Chemical Society, vol. 125, no. 39, pp. 1180211803, 2003.

[25] M. L. Daly, Y. Gao, and R. Freeman, "Encoding reversible hierarchical structures with supramolecular peptide-DNA materials," Bioconjugate Chemistry, vol. 30, no. 7, pp. 18641869, 2019.

[26] R. Freeman, ,M. Han, Z. Álvarez et al., "Reversible selfassembly of superstructured networks," Science, vol. 362, no. 6416, pp. 808-813, 2018.

[27] R. D. A. A. Rajapaksha, "7 - Self-assembling smart materials for biomaterials applications," in Polymer NanocompositeBased Smart Materials, R. Bouhfid, A. E. K. Qaiss, and M. Jawaid, Eds., pp. 121-147, Woodhead Publishing, 2020.

[28] N. Nandi, K. Gayen, S. Ghosh et al., "Amphiphilic peptidebased supramolecular, noncytotoxic, stimuli-responsive hydrogels with antibacterial activity," Biomacromolecules, vol. 18, no. 11, pp. 3621-3629, 2017.

[29] B. Guo and P. X. Ma, "Synthetic biodegradable functional polymers for tissue engineering: a brief review," Science China Chemistry, vol. 57, no. 4, pp. 490-500, 2014.

[30] P. Zorlutuna, N. Annabi, G. Camci-Unal et al., "Microfabricated biomaterials for engineering 3D tissues," Advanced Materials, vol. 24, no. 14, pp. 1782-1804, 2012.

[31] J. Kundu, F. Pati, Y. Hun Jeong, and D.-W. Cho, "Chapter 2 biomaterials for biofabrication of 3D tissue scaffolds," in Biofabrication, G. Forgacs and W. Sun, Eds., pp. 23-46, William Andrew Publishing, Boston, 2013.

[32] J. L. Drury and D. J. Mooney, "Hydrogels for tissue engineering: scaffold design variables and applications," Biomaterials, vol. 24, no. 24, pp. 4337-4351, 2003.

[33] C. D. Spicer, "Hydrogel scaffolds for tissue engineering: the importance of polymer choice," Polymer Chemistry, vol. 11, no. 2, pp. 184-219, 2020.

[34] A. C. Wan, "Recapitulating Cell-Cell Interactions for Organoid Construction - Are Biomaterials Dispensable?," Trends in Biotechnology, vol. 34, no. 9, pp. 711-721, 2016.

[35] P. S. Thakuri, C. Liu, G. D. Luker, and H. Tavana, "Biomaterials-based approaches to tumor spheroid and organoid modeling," Advanced Healthcare Materials, vol. 7, no. 6, 2018.

[36] D. F. Williams, "Challenges with the development of biomaterials for sustainable tissue engineering," Frontiers in Bioengineering and Biotechnology, vol. 7, no. 127, 2019.

[37] A. da Silva Morais, S. Vieira, X. Zhao et al., "Advanced biomaterials and processing methods for liver regeneration: state-of-the-art and future trends," Advanced Healthcare Materials, vol. 9, no. 5, p. 1901435, 2020.

[38] E. A. Guzzi and M. W. Tibbitt, "Additive manufacturing of precision biomaterials," Advanced Materials, vol. 32, no. 13, p. 1901994, 2020.
[39] S. Abdulghani and G. R. Mitchell, "Biomaterials for in situ tissue regeneration: a review," Biomolecules, vol. 9, no. 11, p. 750, 2019.

[40] A. K. Gaharwar, I. Singh, and A. Khademhosseini, "Engineered biomaterials for in situ tissue regeneration," Nature Reviews Materials, vol. 5, no. 9, pp. 686-705, 2020.

[41] E. Mariani, G. Lisignoli, R. M. Borzì, and L. Pulsatelli, "Biomaterials: foreign bodies or tuners for the immune response?," International Journal of Molecular Sciences, vol. 20, no. 3, p. 636, 2019.

[42] B. A. Badeau and C. A. DeForest, "Programming stimuliresponsive behavior into biomaterials," Annual Review of Biomedical Engineering, vol. 21, no. 1, pp. 241-265, 2019.

[43] F. M. Fumasi, N. Stephanopoulos, and J. L. Holloway, "Reversible control of biomaterial properties for dynamically tuning cell behavior," Journal of Applied Polymer Science, vol. 137 , no. 25 , p. $49058,2020$.

[44] W. Wang, R. Narain, and H. Zeng, "Rational design of selfhealing tough hydrogels: a mini review," Frontiers in Chemistry, vol. 6, 2018

[45] S. D. Menikheim and E. B. Lavik, "Self-healing biomaterials: the next generation is nano," WIREs Nanomedicine and Nanobiotechnology, vol. 12, no. 6, p. e1641, 2020.

[46] A. Chansaenroj, S. Yodmuang, and J. N. Ferreira, "Trends in salivary gland tissue engineering: from stem cells to secretome and organoid bioprinting," Tissue Engineering Part B: Reviews, 2020.

[47] J. He, X. Zhang, X. Xia et al., "Organoid technology for tissue engineering," Journal of Molecular Cell Biology, vol. 12, no. 8, pp. 569-579, 2020.

[48] H. Zhang, L. Zhou, and W. Zhang, "Control of scaffold degradation in tissue engineering: a review," Tissue Engineering Part B: Reviews, vol. 20, no. 5, pp. 492-502, 2014.

[49] B. Laycock, M. Nikolić, J. M. Colwell et al., "Lifetime prediction of biodegradable polymers," Progress in Polymer Science, vol. 71, pp. 144-189, 2017.

[50] A. Szent-Gyorgyi, "The supra- and submolecular in biology," Journal of Theoretical Biology, vol. 1, no. 1, pp. 75-82, 1961.

[51] H. Staudinger, "Über polymerisation," Berichte der deutschen chemischen Gesellschaft (A and B Series), vol. 53, no. 6, pp. 1073-1085, 1920.

[52] A. L. Lehninger, "Supramolecular organization of enzyme and membrane systems," Naturwissenschaften, vol. 53, no. 3, pp. 57-63, 1966.

[53] R. B. Merrifield, "Solid phase peptide synthesis. I. The synthesis of a tetrapeptide," Journal of the American Chemical Society, vol. 85, no. 14, pp. 2149-2154, 1963.

[54] D. Andreu, R. B. Merrifield, H. Steiner, and H. G. Boman, "Solid-phase synthesis of cecropin A and related peptides," Proceedings of the National Academy of Sciences of the United States of America, vol. 80, no. 21, pp. 6475-6479, 1983.

[55] S. Mojsov and R. B. Merrifield, "Solid-phase synthesis of crystalline glucagon," Biochemistry, vol. 20, no. 10, pp. 29502956, 2002.

[56] B. F. Gisin, R. B. Merrifield, and D. C. Tosteson, "Solid-phase synthesis of the cyclododecadepsipeptide valinomycin," Journal of the American Chemical Society, vol. 91, no. 10, pp. 2691-2695, 1969.

[57] H. G. Khorana, "Nucleic acid synthesis," Pure and Applied Chemistry, vol. 17, no. 3-4, pp. 349-382, 1968. 
[58] Y. Zhu, T. Tyrikos-Ergas, K. Schiefelbein, A. Grafmuller, P. H. Seeberger, and M. Delbianco, "Automated access to well-defined ionic oligosaccharides," Organic \& Biomolecular Chemistry, vol. 18, no. 7, pp. 1349-1353, 2020.

[59] A. A. Joseph, A. Pardo-Vargas, and P. H. Seeberger, "Total synthesis of polysaccharides by automated glycan assembly," Journal of the American Chemical Society $\backslash$, vol. 142, no. 19, pp. 8561-8564, 2020.

[60] A. Longchamp, K. Kaur, D. Macabrey et al., "Hydrogen sulfide-releasing peptide hydrogel limits the development of intimal hyperplasia in human vein segments," Acta Biomaterialia, vol. 97, pp. 374-384, 2019.

[61] S. Obuobi, H. K. L. Tay, N. D. T. Tram et al., "Facile and efficient encapsulation of antimicrobial peptides via crosslinked DNA nanostructures and their application in wound therapy," Journal of Controlled Release, vol. 313, pp. 120-130, 2019.

[62] Y. J. Zhou, S. Liu, M. Zhao et al., "Injectable extracellular vesicle-released self-assembling peptide nanofiber hydrogel as an enhanced cell-free therapy for tissue regeneration," Journal of Controlled Release, vol. 316, pp. 93-104, 2019.

[63] D. Kumar, V. L. Workman, M. O'Brien et al., "Peptide hydrogels-a tissue engineering strategy for the prevention of oesophageal strictures," Advanced Functional Materials, vol. 27, no. 38, p. 1702424, 2017.

[64] L. A. Castillo Diaz, M. Elsawy, A. Saiani, J. E. Gough, and A. F. Miller, "Osteogenic differentiation of human mesenchymal stem cells promotes mineralization within a biodegradable peptide hydrogel," Journal of Tissue Engineering, vol. 7, Article ID 204173141664978, 2016.

[65] X. Zheng, Z. Ding, W. Cheng et al., "Microskin-inspired injectable MSC-laden hydrogels for scarless wound healing with hair follicles," Advanced Healthcare Materials, vol. 9, no. 10, p. 2000041, 2020.

[66] Y. Loo, A. Lakshmanan, M. Ni, L. L. Toh, S. Wang, and C. A. Hauser, "Peptide bioink: self-assembling nanofibrous scaffolds for three-dimensional organotypic cultures," Nano Letters, vol. 15, no. 10, pp. 6919-6925, 2015.

[67] Y. Loo, Y. S. Chan, I. Szczerbinska et al., "A chemically welldefined, self-assembling 3D substrate for long-term culture of human pluripotent stem cells," ACS Applied Biomaterials, vol. 2, no. 4, pp. 1406-1412, 2019.

[68] J. Conde, N. Oliva, M. Atilano, H. S. Song, and N. Artzi, "Selfassembled RNA-triple-helix hydrogel scaffold for microRNA modulation in the tumour microenvironment," Nature Materials, vol. 15, no. 3, pp. 353-363, 2016.

[69] M. S. Ekiz, G. Cinar, M. A. Khalily, and M. O. Guler, "Selfassembled peptide nanostructures for functional materials," Nanotechnology, vol. 27, no. 40, p. 402002, 2016.

[70] F. Herbst, D. Döhler, P. Michael, and W. H. Binder, "Selfhealing polymers via supramolecular forces," Macromolecular Rapid Communications, vol. 34, no. 3, pp. 203-220, 2013.

[71] M. J. Hannon, "Supramolecular DNA recognition," Chemical Society Reviews, vol. 36, no. 2, pp. 280-295, 2007.

[72] P. Yakovchuk, E. Protozanova, and M. D. Frank-Kamenetskii, "Base-stacking and base-pairing contributions into thermal stability of the DNA double helix," Nucleic Acids Research, vol. 34, no. 2, pp. 564-574, 2006.

[73] P. L. Privalov and C. Crane-Robinson, "Forces maintaining the DNA double helix," European Biophysics Journal, vol. 49, no. 5, pp. 315-321, 2020.
[74] S. E. Butcher and A. M. Pyle, "The molecular interactions that stabilize RNA tertiary structure: RNA motifs, patterns, and networks," Accounts of Chemical Research, vol. 44, no. 12, pp. 1302-1311, 2011.

[75] K. H. Chan, W. H. Lee, M. Ni, Y. Loo, and C. A. E. Hauser, "C-Terminal Residue of Ultrashort Peptides Impacts on Molecular Self- Assembly, Hydrogelation, and Interaction with Small-Molecule Drugs," Scientific Reports, vol. 8, no. 1, 2018.

[76] C. A. E. Hauser, R. Deng, A. Mishra et al., "Natural tri- to hexapeptides self-assemble in water to amyloid-type fiber aggregates by unexpected -helical intermediate structures," Proceedings of the National Academy of Sciences, vol. 108, no. 4, pp. 1361-1366, 2011.

[77] J. Wang, K. Liu, R. Xing, and X. Yan, "Peptide self-assembly: thermodynamics and kinetics," Chemical Society Reviews, vol. 45, no. 20, pp. 5589-5604, 2016.

[78] Y. Sun and C. Kang, "Self-assembly of peptides into hydrogel," Journal of Organic \& Inorganic Chemistry, vol. 2, no. 1, 2016.

[79] X. Zhao, F. Pan, H. Xu et al., "Molecular self-assembly and applications of designer peptide amphiphiles," Chemical Society Reviews, vol. 39, no. 9, pp. 3480-3498, 2010.

[80] A. Dehsorkhi, V. Castelletto, and I. W. Hamley, "Self-assembling amphiphilic peptides," Journal of Peptide Science, vol. 20, no. 7, pp. 453-467, 2014.

[81] M. W. Krone, C. R. Travis, G. Y. Lee, H. J. Eckvahl, K. N. Houk, and M. L. Waters, "More than $\pi-\pi-\pi$ stacking: contribution of amide $-\pi$ and $\mathrm{CH}-\pi$ interactions to crotonyllysine binding by the AF9 YEATS domain," Journal of the American Chemical Society, vol. 142, no. 40, pp. 17048-17056, 2020.

[82] Y. Liu, L. Zhang, and W. Wei, "Effect of noncovalent interaction on the self-assembly of a designed peptide and its potential use as a carrier for controlled bFGF release," International Journal of Nanomedicine, vol. Volume 12, pp. 659-670, 2017.

[83] W. Chanasit, Z. J. C. Gonzaga, and B. H. A. Rehm, "Analysis of the alginate $\mathrm{O}$-acetylation machinery in Pseudomonas aeruginosa," Applied Microbiology and Biotechnology, vol. 104, no. 5, pp. 2179-2191, 2020.

[84] V. Bertacche, N. Lorenzi, D. Nava, E. Pini, and C. Sinico, "Host-guest interaction study of resveratrol with natural and modified cyclodextrins," Journal of Inclusion Phenomena and Macrocyclic Chemistry, vol. 55, no. 3-4, pp. 279-287, 2006.

[85] R. Challa, A. Ahuja, J. Ali, and R. Khar, "Cyclodextrins in drug delivery: an updated review," AAPS PharmSciTech, vol. 6, no. 2, pp. E329-E357, 2005.

[86] S. Zhang, T. Holmes, C. Lockshin, and A. Rich, "Spontaneous assembly of a self-complementary oligopeptide to form a stable macroscopic membrane," Proceedings of the National Academy of Sciences, vol. 90, no. 8, pp. 33343338, 1993.

[87] S. Zhang, C. Lockshin, A. Herbert, E. Winter, and A. Rich, "Zuotin, a putative Z-DNA binding protein in Saccharomyces cerevisiae," The EMBO Journal, vol. 11, no. 10, pp. 3787-3796, 1992.

[88] C. J. Pike, D. Burdick, A. J. Walencewicz, C. G. Glabe, and C. W. Cotman, "Neurodegeneration induced by betaamyloid peptides in vitro: the role of peptide assembly state," The Journal of Neuroscience, vol. 13, no. 4, pp. 1676-1687, 1993. 
[89] B. Soreghan, J. Kosmoski, and C. Glabe, "Surfactant properties of Alzheimer's A beta peptides and the mechanism of amyloid aggregation," Journal of Biological Chemistry, vol. 269, no. 46, pp. 28551-28554, 1994.

[90] R. Jayakumar, C. Jayanthy, and L. Gomathy, "Peptide aggregates: a novel model system to study self-assembly of peptides," International Journal of Peptide and Protein Research, vol. 45, no. 2, pp. 129-137, 1995.

[91] A. Aggeli, M. Bell, N. Boden et al., "Responsive gels formed by the spontaneous self-assembly of peptides into polymeric $\beta$ sheet tapes," Nature, vol. 386, no. 6622, pp. 259-262, 1997.

[92] L. Wang, S. K. Murthy, W. H. Fowle, G. A. Barabino, and R. L. Carrier, "Influence of micro-well biomimetic topography on intestinal epithelial Caco-2 cell phenotype," Biomaterials, vol. 30, no. 36, pp. 6825-6834, 2009.

[93] H. J. Kim, D. Huh, G. Hamilton, and D. E. Ingber, "Human gut-on-a-chip inhabited by microbial flora that experiences intestinal peristalsis-like motions and flow," Lab on a Chip, vol. 12, no. 12, pp. 2165-2174, 2012.

[94] A. Lakshmanan, D. W. Cheong, A. Accardo, E. Di Fabrizio, C. Riekel, and C. A. E. Hauser, "Aliphatic peptides show similar self-assembly to amyloid core sequences, challenging the importance of aromatic interactions in amyloidosis," Proceedings of the National Academy of Sciences, vol. 110, no. 2, pp. 519-524, 2013.

[95] Y. Loo, Y. C. Wong, E. Z. Cai et al., "Ultrashort peptide nanofibrous hydrogels for the acceleration of healing of burn wounds," Biomaterials, vol. 35, no. 17, pp. 4805-4814, 2014.

[96] W. Y. Seow, G. Salgado, E. B. Lane, and C. A. Hauser, "Transparent crosslinked ultrashort peptide hydrogel dressing with high shape-fidelity accelerates healing of full-thickness excision wounds," Scientific Reports, vol. 6, no. 1, p. 32670, 2016.

[97] M. R. Reithofer, K. H. Chan, A. Lakshmanan et al., "Ligation of anti-cancer drugs to self-assembling ultrashort peptides by click chemistry for localized therapy," Chemical Science, vol. 5, no. 2, pp. 625-630, 2014.

[98] S. Ghalayini, H. H. Susapto, S. Hall, K. Kahin, and C. A. E. Hauser, "Preparation and printability of ultrashort selfassembling peptide nanoparticles," International Journal of Bioprinting, vol. 5, no. 2, p. 239, 2019.

[99] M. Ni, G. Tresset, C. Iliescu, and C. A. E. Hauser, "Ultrashort peptide theranostic nanoparticles by microfluidic-assisted rapid solvent exchange," IEEE Transactions on NanoBioscience, vol. 19, no. 4, pp. 627-632, 2020.

[100] E. Di Fabrizio, S. Schlücker, J. Wenger et al., "Roadmap on biosensing and photonics with advanced nano-optical methods," Journal of Optics, vol. 18, no. 6, article 063003, 2016.

[101] M. Ni, S. Zhuo, C. Iliescu et al., "Self-assembling amyloid-like peptides as exogenous second harmonic probes for bioimaging applications," Journal of Biophotonics, vol. 12, no. 12, article e201900065, 2019.

[102] I. Insua and J. Montenegro, "1D to 2 D self assembly of cyclic peptides," Journal of the American Chemical Society, vol. 142, no. 1, pp. 300-307, 2019.

[103] J. Shi, G. Fichman, and J. P. Schneider, "Enzymatic control of the conformational landscape of self-assembling peptides," Angewandte Chemie-International Edition, vol. 57, no. 35, pp. 11188-11192, 2018.

[104] K. Nagy-Smith, E. Moore, J. Schneider, and R. Tycko, "Molecular structure of monomorphic peptide fibrils within a kinetically trapped hydrogel network," Proceedings of the National Academy of Sciences of the United States of America, vol. 112, no. 32, pp. 9816-9821, 2015.

[105] P. K. Gavel, N. Kumar, H. S. Parmar, and A. K. Das, "Evaluation of a peptide-based coassembled nanofibrous and thixotropic hydrogel for dermal wound healing," ACS Applied Bio Materials, vol. 3, no. 5, pp. 3326-3336, 2020.

[106] X. D. Kong, J. Moriya, V. Carle et al., "De novo development of proteolytically resistant therapeutic peptides for oral administration," Nature Biomedical Engineering, vol. 4, no. 5, pp. 560-571, 2020.

[107] D. Umeno, T. Kano, and M. Maeda, "Affinity adsorption separation of mutagenic molecules by polyacrylamide hydrogels comprising double-stranded DNA," Analytica Chimica Acta, vol. 365, no. 1-3, pp. 101-108, 1998.

[108] J. S. Kahn, A. Trifonov, A. Cecconello, W. Guo, C. Fan, and I. Willner, "Integration of switchable DNA-based hydrogels with surfaces by the hybridization chain reaction," Nano Letters, vol. 15, no. 11, pp. 7773-7778, 2015.

[109] S. H. Um, J. B. Lee, N. Park, S. Y. Kwon, C. C. Umbach, and D. Luo, "Enzyme-catalysed assembly of DNA hydrogel," Nature Materials, vol. 5, no. 10, pp. 797-801, 2006.

[110] Y. J. Wang, Y. Shao, X. Ma et al., "Constructing tissuelike complex structures using cell-laden DNA hydrogel bricks," ACS Applied Materials \& Interfaces, vol. 9, no. 14, pp. 12311-12315, 2017.

[111] Y. Sato, T. Sakamoto, and M. Takinoue, "Sequence-based engineering of dynamic functions of micrometer-sized DNA droplets," Science Advances, vol. 6, no. 23, article eaba3471, 2020.

[112] H. Yuan, C. Chen, Y. Liu, T. Lu, and Z. Wu, "Strategies in cell-free tissue-engineered vascular grafts," Journal of Biomedical Materials Research Part A, vol. 108, no. 3, pp. 426$445,2020$.

[113] J. Cui, D. Wu, Q. Sun et al., "A PEGDA/DNA hybrid hydrogel for cell-free protein synthesis," Frontiers in Chemistry, vol. 8, p. 28, 2020.

[114] C. Yao, H. Tang, W. Wu et al., "Double rolling circle amplification generates physically cross-linked DNA network for stem cell fishing," Journal of the American Chemical Society, vol. 142, no. 7, pp. 3422-3429, 2020.

[115] H. Qi, M. Ghodousi, Y. du et al., "DNA-directed selfassembly of shape-controlled hydrogels," Nature Communications, vol. 4, no. 1, p. 2275, 2013.

[116] C. Du and R. J. Hill, "Complementary-DNA-strand crosslinked polyacrylamide hydrogels,", Macromolecules, vol. 52, no. 17, pp. 6683-6697, 2019.

[117] A. J. Anderson, H. R. Culver, S. J. Bryant, and C. N. Bowman, "Viscoelastic and thermoreversible networks crosslinked by non-covalent interactions between "clickable" nucleic acid oligomers and DNA," Polymer Chemistry, vol. 11, no. 17, pp. 2959-2968, 2020.

[118] M. A. English, L. R. Soenksen, R. V. Gayet et al., "Programmable CRISPR-responsive smart materials," Science, vol. 365, no. 6455, pp. 780-785, 2019.

[119] F. Li, D. Lyu, S. Liu, and W. Guo, "DNA hydrogels and microgels for biosensing and biomedical applications," Advanced Materials, vol. 32, no. 3, article e1806538, 2020.

[120] J. Chen, Y. Zhu, H. Liu, and L. Wang, "Tailoring DNA selfassembly to build hydrogels," Topics in Current Chemistry, vol. 378 , no. 2 , p. $32,2020$. 
[121] D. Xu, K. Arnold, and J. Liu, "Using structurally defined oligosaccharides to understand the interactions between proteins and heparan sulfate," Current Opinion in Structural Biology, vol. 50, pp. 155-161, 2018.

[122] A. Kumar and A. Kumar, "The virtuous potential of chitosan oligosaccharide for promising biomedical applications," Journal of Materials Research, vol. 35, no. 9, pp. 1123-1134, 2020.

[123] E. A. Turley, P. W. Noble, and L. Y. Bourguignon, "Signaling properties of hyaluronan receptors," Journal of Biological Chemistry, vol. 277, no. 7, pp. 4589-4592, 2002.

[124] L. Kang, W. Jia, M. Li et al., "Hyaluronic acid oligosaccharidemodified collagen nanofibers as vascular tissue-engineered scaffold for promoting endothelial cell proliferation," Carbohydrate Polymers, vol. 223, p. 115106, 2019.

[125] M. Li, X. Zhang, W. Jia et al., "Improving in vitro biocompatibility on biomimetic mineralized collagen bone materials modified with hyaluronic acid oligosaccharide," Materials Science \& Engineering. C, Materials for Biological Applications, vol. 104, p. 110008, 2019.

[126] X. Lv, Y. Liu, S. Song et al., "Influence of chitosan oligosaccharide on the gelling and wound healing properties of injectable hydrogels based on carboxymethyl chitosan/alginate polyelectrolyte complexes," Carbohydrate Polymers, vol. 205, pp. 312-321, 2019.

[127] G. Sandri, C. Aguzzi, S. Rossi et al., "Halloysite and chitosan oligosaccharide nanocomposite for wound healing," Acta Biomaterialia, vol. 57, pp. 216-224, 2017.

[128] C. Muanprasat and V. Chatsudthipong, "Chitosan oligosaccharide: biological activities and potential therapeutic applications," Pharmacology \& Therapeutics, vol. 170, pp. 80-97, 2017.

[129] L. Shi, B. Fang, Y. Yong et al., "Chitosan oligosaccharidemediated attenuation of LPS-induced inflammation in IPEC-J2 cells is related to the TLR4/NF- $\kappa \mathrm{B}$ signaling pathway," Carbohydrate Polymers, vol. 219, pp. 269-279, 2019.

[130] K. Toshima and K. Tatsuta, "Recent progress in Oglycosylation methods and its application to naturalproducts synthesis," Chemical Reviews, vol. 93, no. 4, pp. 1503-1531, 1993.

[131] K. M. Yamada and M. Sixt, "Mechanisms of 3D cell migration," Nature Reviews Molecular Cell Biology, vol. 20, no. 12, pp. 738-752, 2019.

[132] I. Apsite, J. M. Uribe, A. F. Posada, S. Rosenfeldt, S. Salehi, and L. Ionov, " $4 \mathrm{D}$ biofabrication of skeletal muscle microtissues," Biofabrication, vol. 12, no. 1, article 015016, 2019.

[133] C. Zuppinger, "3D cardiac cell culture: a critical review of current technologies and applications," Frontiers in Cardiovascular Medicine, vol. 6, p. 87, 2019.

[134] B. Widholz, S. Tsitlakidis, B. Reible, A. Moghaddam, and F. Westhauser, "Pooling of patient-derived mesenchymal stromal cells reduces inter-individual confounder-associated variation without negative impact on cell viability, proliferation and osteogenic differentiation," Cells, vol. 8, no. 6, p. 633, 2019.

[135] M. del Carmen Ortuño-Costela, M. García-López, V. Cerrada, and M. E. Gallardo, "iPSCs: a powerful tool for skeletal muscle tissue engineering," Journal of Cellular and Molecular Medicine, vol. 23, no. 6, pp. 3784-3794, 2019.

[136] J. A. Brassard and M. P. Lutolf, "Engineering stem cell selforganization to build better organoids," Cell Stem Cell, vol. 24 , no. 6, pp. 860-876, 2019.
[137] K. H. Hillebrandt, H. Everwien, N. Haep, E. Keshi, J. Pratschke, and I. M. Sauer, "Strategies based on organ decellularization and recellularization," Transplant International, vol. 32, no. 6, pp. 571-585, 2019.

[138] M. Mabrouk, H. H. Beherei, and D. B. Das, "Recent progress in the fabrication techniques of $3 \mathrm{D}$ scaffolds for tissue engineering," Materials Science and Engineering: C, vol. 110, article 110716, 2020.

[139] T. Tsuchiya, R. Doi, T. Obata, G. Hatachi, and T. Nagayasu, "Lung microvascular niche, repair, and engineering," Frontiers in Bioengineering and Biotechnology, vol. 8, no. 105, 2020.

[140] J. Rubert, P. J. Schweiger, F. Mattivi, K. Tuohy, K. B. Jensen, and A. Lunardi, "Intestinal organoids: a tool for modelling diet-microbiome-host interactions," Trends in Endocrinology and Metabolism, vol. 31, no. 11, pp. 848-858, 2020.

[141] A. Fatehullah, S. H. Tan, and N. Barker, "Organoids as an in vitro model of human development and disease," Nature Cell Biology, vol. 18, no. 3, pp. 246-254, 2016.

[142] R. Subbiah and R. E. Guldberg, "Materials science and design principles of growth factor delivery systems in tissue engineering and regenerative medicine," Advanced Healthcare Materials, vol. 8, no. 1, p. 1801000, 2019.

[143] W. Ha, Z. H. Wang, X. B. Zhao, and Y. P. Shi, "Reinforced supramolecular hydrogels from attapulgite and cyclodextrin pseudopolyrotaxane for sustained intra-articular drug delivery," Macromolecular Bioscience, p. 2000299, 2020.

[144] C. Fiorica, F. S. Palumbo, G. Pitarresi et al., "A hyaluronic acid/cyclodextrin based injectable hydrogel for local doxorubicin delivery to solid tumors," International Journal of Pharmaceutics, vol. 589, p. 119879, 2020.

[145] H. J. Lee, P. T. Le, H. J. Kwon, and K. D. Park, "Supramolecular assembly of tetronic-adamantane and poly ( $\beta$-cyclodextrin) as injectable shear-thinning hydrogels," Journal of Materials Chemistry B, vol. 7, no. 21, pp. 3374-3382, 2019.

[146] A. Rey-Rico and M. Cucchiarini, "Supramolecular cyclodextrin-based hydrogels for controlled gene delivery," Polymers, vol. 11, no. 3, p. 514, 2019.

[147] Q. Wang, N. Jiang, B. Fu, F. Huang, and J. Liu, "Self-assembling peptide-based nanodrug delivery systems," Biomaterials Science, vol. 7, no. 12, pp. 4888-4911, 2019.

[148] M. Tao, J. Liu, S. He, K. Xu, and W. Zhong, "In situ hydrogelation of forky peptides in prostate tissue for drug delivery," Soft Matter, vol. 15, no. 20, pp. 4200-4207, 2019.

[149] Q. Zhang, Q. Jiang, N. Li et al., "DNA origami as an in vivo drug delivery vehicle for cancer therapy," ACS Nano, vol. 8, no. 7, pp. 6633-6643, 2014.

[150] Q. Jiang, S. Liu, J. Liu, Z.-G. Wang, and B. Ding, "Rationally designed DNA-origami nanomaterials for drug delivery in vivo," Advanced Materials, vol. 31, no. 45, article 1804785, 2019.

[151] Z. Ge, L. Guo, G. Wu et al., "DNA origami-enabled engineering of ligand-drug conjugates for targeted drug delivery," Small, vol. 16, no. 16, article 1904857, 2020.

[152] R. K. Jain, P. Au, J. Tam, D. G. Duda, and D. Fukumura, "Engineering vascularized tissue," Nature Biotechnology, vol. 23, no. 7, pp. 821-823, 2005.

[153] N. Asakawa, T. Shimizu, Y. Tsuda et al., "Pre-vascularization of in vitro three-dimensional tissues created by cell sheet engineering," Biomaterials, vol. 31, no. 14, pp. 3903-3909, 2010 . 
[154] K. H. Hussein, K.-M. Park, L. Yu, S.-H. Song, H.-M. Woo, and H.-H. Kwak, "Vascular reconstruction: a major challenge in developing a functional whole solid organ graft from decellularized organs," Acta Biomaterialia, vol. 103, pp. 68-80, 2020.

[155] L. E. Bertassoni, M. Cecconi, V. Manoharan et al., "Hydrogel bioprinted microchannel networks for vascularization of tissue engineering constructs," Lab on a Chip, vol. 14, no. 13, pp. 2202-2211, 2014.

[156] J. Rouwkema and A. Khademhosseini, "Vascularization and angiogenesis in tissue engineering: beyond creating static networks," Trends in Biotechnology, vol. 34, no. 9, pp. 733-745, 2016.

[157] M. A. Ruehle, E. A. Eastburn, S. A. LaBelle et al., "Extracellular matrix compression temporally regulates microvascular angiogenesis," Science Advances, vol. 6, no. 34, article eabb6351, 2020.

[158] J. Qi, Y. Yan, B. Cheng et al., "Enzymatic formation of an injectable hydrogel from a glycopeptide as a biomimetic scaffold for vascularization," ACS Applied Materials \& Interfaces, vol. 10, no. 7, pp. 6180-6189, 2018.

[159] Y. Zheng, W. Yuan, H. Liu, S. Huang, L. Bian, and R. Guo, "Injectable supramolecular gelatin hydrogel loading of resveratrol and histatin-1 for burn wound therapy," Biomaterials Science, vol. 8, no. 17, pp. 4810-4820, 2020.

[160] J.-H. Lee, P. Parthiban, G.-Z. Jin, J. C. Knowles, and H.W. Kim, "Materials roles for promoting angiogenesis in tissue regeneration," Progress in Materials Science, no. article 100732, 2020.

[161] T. Takebe, B. Zhang, and M. Radisic, "Synergistic engineering: organoids meet organs-on-a-chip," Cell Stem Cell, vol. 21, no. 3, pp. 297-300, 2017.

[162] M. J. Kratochvil, A. J. Seymour, T. L. Li, S. P. Paşca, C. J. Kuo, and S. C. Heilshorn, "Engineered materials for organoid systems," Nature Reviews Materials, vol. 4, no. 9, pp. 606-622, 2019.

[163] L. C. Bahlmann, A. Fokina, and M. S. Shoichet, "Dynamic bioengineered hydrogels as scaffolds for advanced stem cell and organoid culture," MRS Communications, vol. 7, no. 3, pp. 472-486, 2017.

[164] L. Saunders and P. X. Ma, "Self-healing supramolecular hydrogels for tissue engineering applications," Macromolecular Bioscience, vol. 19, no. 1, article 1800313, 2019.

[165] L. Cai, S. Liu, J. Guo, and Y.-G. Jia, "Polypeptide-based selfhealing hydrogels: design and biomedical applications," Acta Biomaterialia, vol. 113, pp. 84-100, 2020.

[166] P. Ren, J. Li, L. Zhao et al., "Dipeptide self-assembled hydrogels with shear-thinning and instantaneous self-healing properties determined by peptide sequences," ACS Applied Materials \& Interfaces, vol. 12, no. 19, pp. 21433-21440, 2020.

[167] W. L. Ng, C. K. Chua, and Y.-F. Shen, "Print me an organ! Why we are not there yet," Progress in Polymer Science, vol. 97, p. 101145, 2019.

[168] J. M. Lee, W. L. Ng, and W. Y. Yeong, "Resolution and shape in bioprinting: strategizing towards complex tissue and organ printing," Applied Physics Reviews, vol. 6, no. 1, article 011307, 2019.

[169] W. L. Ng, A. Chan, Y. S. Ong, and C. K. Chua, “Deep learning for fabrication and maturation of 3D bioprinted tissues and organs," Virtual and Physical Prototyping, vol. 15, no. 3, pp. 340-358, 2020.
[170] M. Vaidya, "Startups tout commercially 3D-printed tissue for drug screening," Nature Medicine, vol. 21, no. 1, p. 2, 2015.

[171] T. A. Mir, S. Iwanaga, T. Kurooka, H. Toda, S. Sakai, and M. Nakamura, "Biofabrication offers future hope for tackling various obstacles and challenges in tissue engineering and regenerative medicine: A Prospective," International Journal of Bioprinting, vol. 5, no. 1, 2019.

[172] I. T. Ozbolat and M. Hospodiuk, "Current advances and future perspectives in extrusion-based bioprinting," Biomaterials, vol. 76, pp. 321-343, 2016.

[173] C. Silva, C. J. Cortés-Rodriguez, J. Hazur, S. Reakasame, and A. R. Boccaccini, "Rational design of a triple-layered coaxial extruder system: in silico and in vitro evaluations directed toward optimizing cell viability," International Journal of Bioprinting, vol. 6, no. 4, 2020.

[174] H. Gudapati, M. Dey, and I. Ozbolat, "A comprehensive review on droplet-based bioprinting: past, present and future," Biomaterials, vol. 102, pp. 20-42, 2016.

[175] W. L. Ng, J. M. Lee, W. Y. Yeong, and M. W. Naing, "Microvalve-based bioprinting-process, bio-inks and applications," Biomaterials Science, vol. 5, no. 4, pp. 632-647, 2017.

[176] D. Takagi, W. Lin, T. Matsumoto et al., "High-precision 3D inkjet technology for live cell bioprinting," International Journal of Bioprinting, vol. 5, no. 2, 2019.

[177] W. L. Ng, J. M. Lee, M. Zhou et al., "Vat polymerizationbased bioprinting - process, materials, applications and regulatory challenges," Biofabrication, vol. 12, no. 2, article 022001, 2020.

[178] J. Zhang, Q. Hu, S. Wang, J. Tao, and M. Gou, "Digital light processing based three-dimensional printing for medical applications," International Journal of Bioprinting, vol. 6, no. $1,2020$.

[179] L. Moroni, J. A. Burdick, C. Highley et al., "Biofabrication strategies for 3D in vitro models and regenerative medicine," Nature Reviews Materials, vol. 3, no. 5, pp. 21-37, 2018.

[180] B. E. Kelly, I. Bhattacharya, H. Heidari, M. Shusteff, C. M. Spadaccini, and H. K. Taylor, "Volumetric additive manufacturing via tomographic reconstruction," Science, vol. 363, no. 6431, pp. 1075-1079, 2019.

[181] M. Müller, P. Fisch, M. Molnar et al., "Development and thorough characterization of the processing steps of an ink for 3D printing for bone tissue engineering," Materials Science \& Engineering. C, Materials for Biological Applications, vol. 108, p. 110510, 2020.

[182] M. Lee, K. Bae, C. Levinson, and M. Zenobi-Wong, "Nanocomposite bioink exploits dynamic covalent bonds between nanoparticles and polysaccharides for precision bioprinting," Biofabrication, vol. 12, no. 2, article 025025, 2020.

[183] S. W. Kim, D. Y. Kim, H. H. Roh, H. S. Kim, J. W. Lee, and K. Y. Lee, "Three-dimensional bioprinting of cell-laden constructs using polysaccharide-based self-healing hydrogels," Biomacromolecules, vol. 20, no. 5, pp. 1860-1866, 2019.

[184] C. Tondera, R. Wieduwild, E. Roder, C. Werner, Y. X. Zhang, and J. Pietzsch, "In vivo examination of an injectable hydrogel system crosslinked by peptide-oligosaccharide interaction in immunocompetent nude mice," Advanced Functional Materials, vol. 27, no. 15, article 1605189, 2017.

[185] W. T. Arab, A. M. Niyas, K. Seferji, H. H. Susapto, and C. A. E. Hauser, "Evaluation of peptide nanogels for accelerated wound healing in normal micropigs," Frontiers in Nanoscience and Nanotechnology, vol. 4, no. 4, pp. 1-9, 2018. 
[186] C. Li, A. Faulkner-Jones, A. R. Dun et al., "Rapid formation of a supramolecular polypeptide-DNA hydrogel for in situ three-dimensional multilayer bioprinting," Angewandte Chemie International Edition, vol. 54, no. 13, pp. 3957-3961, 2015.

[187] C. M. Niemeyer, M. Adler, S. Gao, and L. Chi, "Supramolecular DNA-streptavidin nanocircles with a covalently attached oligonucleotide moiety," Journal of Biomolecular Structure and Dynamics, vol. 20, no. 2, pp. 223-230, 2002.

[188] C. K. Lee, S. R. Shin, S. H. Lee et al., "DNA hydrogel fiber with self-entanglement prepared by using an ionic liquid," Angewandte Chemie-International Edition, vol. 47, no. 13, pp. 2470-2474, 2008.

[189] S. W. Shin, K. S. Park, M. S. Jang et al., "X-DNA origaminetworked core-supported lipid stratum," Langmuir, vol. 31, no. 3, pp. 912-916, 2015.

[190] M. C. Morán, M. G. Miguel, and B. Lindman, "DNA gel particles from single and double-tail surfactants: supramolecular assemblies and release characteristics," Soft Matter, vol. 7, no. 5, pp. 2001-2010, 2011.

[191] Z. Huang, G. N. Kangovi, W. Wen, S. Lee, and L. Niu, “An RNA aptamer capable of forming a hydrogel by self-assembly," Biomacromolecules, vol. 18, no. 7, pp. 2056-2063, 2017.

[192] J. Gao, C. Tang, M. A. Elsawy, A. M. Smith, A. F. Miller, and A. Saiani, "Controlling self-assembling peptide hydrogel properties through network topology," Biomacromolecules, vol. 18, no. 3, pp. 826-834, 2017.

[193] Y. Hu, J. S. Kahn, W. Guo et al., "Reversible modulation of DNA-based hydrogel shapes by internal stress interactions," Journal of the American Chemical Society, vol. 138, no. 49, pp. 16112-16119, 2016.

[194] P. K. Nguyen, W. Gao, S. D. Patel et al., "Self-assembly of a dentinogenic peptide hydrogel," ACS Omega, vol. 3, no. 6, pp. 5980-5987, 2018.

[195] S. Wan, S. Borland, S. M. Richardson, C. L. R. Merry, A. Saiani, and J. E. Gough, "Self-assembling peptide hydrogel for intervertebral disc tissue engineering," Acta Biomaterialia, vol. 46, pp. 29-40, 2016.

[196] M. Ghosh, M. Halperin-Sternfeld, I. Grinberg, and L. AdlerAbramovich, "Injectable alginate-peptide composite hydrogel as a scaffold for bone tissue regeneration," Nanomaterials, vol. 9, no. 4, 2019.

[197] N. C. Carrejo, A. N. Moore, T. L. Lopez Silva et al., "Multidomain peptide hydrogel accelerates healing of full-thickness wounds in diabetic mice," ACS Biomaterials Science \& Engineering, vol. 4, no. 4, pp. 1386-1396, 2017.

[198] A. N. Moore, T. L. L. Silva, N. C. Carrejo, C. A. O. Marmolejo, I. C. Li, and J. D. Hartgerink, "Nanofibrous peptide hydrogel elicits angiogenesis and neurogenesis without drugs, proteins, or cells," Biomaterials, vol. 161, pp. 154-163, 2018.

[199] S. Motamed, M. P. Del Borgo, K. Kulkarni et al., "A selfassembling beta-peptide hydrogel for neural tissue engineering," Soft Matter, vol. 12, no. 8, pp. 2243-2246, 2016.

[200] M. Sheikholeslam, S. D. Wheeler, K. G. Duke, M. Marsden, M. Pritzker, and P. Chen, "Peptide and peptide-carbon nanotube hydrogels as scaffolds for tissue \& $3 \mathrm{D}$ tumor engineering," Acta Biomaterialia, vol. 69, pp. 107-119, 2018.

[201] J. D. Tang, C. Mura, and K. J. Lampe, "Stimuli-responsive, pentapeptide, nanofiber hydrogel for tissue engineering," Journal of the American Chemical Society, vol. 141, no. 12, pp. 4886-4899, 2019.
[202] H. Jin, C. Wan, Z. Zou et al., "Tumor ablation and therapeutic immunity induction by an injectable peptide hydrogel," ACS Nano, vol. 12, no. 4, pp. 3295-3310, 2018.

[203] P. Hitscherich, P. K. Nguyen, A. Kannan et al., "Injectable self-assembling peptide hydrogels for tissue writing and embryonic stem cell culture," Journal of Biomedical Nanotechnology, vol. 14, no. 4, pp. 802-807, 2018.

[204] E. Cheng, Y. Xing, P. Chen et al., "A pH-triggered, fastresponding DNA hydrogel," Angewandte ChemieInternational Edition, vol. 48, no. 41, pp. 7660-7663, 2009.

[205] H. Y. Jia, J. Z. Shi, Y. Shao, and D. S. Liu, "DNA hydrogels formed of bended DNA scaffolds and properties study," Chinese Journal of Polymer Science, vol. 35, no. 10, pp. 13071314, 2017.

[206] T. Wang, Y. Zheng, Y. Shi, and L. Zhao, "pH-responsive calcium alginate hydrogel laden with protamine nanoparticles and hyaluronan oligosaccharide promotes diabetic wound healing by enhancing angiogenesis and antibacterial activity," Drug Delivery and Translational Research, vol. 9, no. 1, pp. 227-239, 2019.

[207] X. Li, M. Fu, J. Wu et al., "pH-sensitive peptide hydrogel for glucose-responsive insulin delivery," Acta Biomaterialia, vol. 51, pp. 294-303, 2017.

[208] F. Wang, R.-b. Zhong, Q. Tang et al., "An ATP-responsive linear DNA hydrogel," Acta Polymerica Sinica, no. 5, pp. 553-558, 2018.

[209] W. Guo, C. Yang, L. Cui, H. Lin, and F. Qu, "An enzymeresponsive controlled release system of mesoporous silica coated with konjac oligosaccharide," Langmuir, vol. 30, no. 1, pp. 243-249, 2014.

[210] N. D. Mansukhani, L. M. Guiney, Z. Wei et al., "Optothermally reversible carbon nanotube-DNA supramolecular hybrid hydrogels," Macromolecular Rapid Communications, vol. 39, no. 2, article 1700587, 2018.

[211] Y. Si, L. Xu, N. Wang, J. Zheng, R. Yang, and J. Li, “Target microRNA-responsive DNA hydrogel-based surfaceenhanced Raman scattering sensor arrays for microRNAmarked cancer screening," Analytical Chemistry, vol. 92, no. 3, pp. 2649-2655, 2020.

[212] A. Roy, P. P. Maity, A. Bose, S. Dhara, and S. Pal, " $\beta$-Cyclodextrin based $\mathrm{pH}$ and thermo-responsive biopolymeric hydrogel as a dual drug carrier," Materials Chemistry Frontiers, vol. 3, no. 3, pp. 385-393, 2019.

[213] A. Roy, P. P. Maity, S. Dhara, and S. Pal, "Biocompatible, stimuli-responsive hydrogel of chemically crosslinked $\beta$ cyclodextrin as amoxicillin carrier," Journal of Applied Polymer Science, vol. 135, no. 10, p. 45939, 2018.

[214] J. Song, K. Im, S. Hwang et al., "DNA hydrogel delivery vehicle for light-triggered and synergistic cancer therapy," Nanoscale, vol. 7, no. 21, pp. 9433-9437, 2015.

[215] Z. Li, G. Davidson-Rozenfeld, M. Vázquez-González et al., "Multi-triggered supramolecular DNA/bipyridinium dithienylethene hydrogels driven by light, redox, and chemical stimuli for shape-memory and self-healing applications," Journal of the American Chemical Society, vol. 140, no. 50, pp. 17691-17701, 2018.

[216] R. Huang, J. Han, R. Wang et al., "Surfactant-free solid dispersion of BCS class IV drug in an amorphous chitosan oligosaccharide matrix for concomitant dissolution in vitro - permeability increase," European Journal of Pharmaceutical Sciences, vol. 130, pp. 147-155, 2019. 
[217] J. Wang, H. Wang, H. Wang et al., "Nonviolent self-catabolic DNAzyme nanosponges for smart anticancer drug delivery," ACS Nano, vol. 13, no. 5, pp. 5852-5863, 2019.

[218] D. Lyu, S. Chen, and W. Guo, "Liposome crosslinked polyacrylamide/DNA hydrogel: a smart controlled-release system for small molecular payloads," Small, vol. 14, no. 15, article e1704039, 2018.

[219] Y. Yamada, N. L. Patel, J. D. Kalen, and J. P. Schneider, "Design of a peptide-based electronegative hydrogel for the direct encapsulation, 3D culturing, in vivo syringe-based delivery, and long-term tissue engraftment of cells," ACS Applied Materials \& Interfaces, vol. 11, no. 38, pp. 3468834697, 2019.

[220] N. Singha, A. Srivastava, B. Pramanik et al., "Unusual confinement properties of a water insoluble small peptide hydrogel," Chemical Science, vol. 10, no. 23, pp. 5920-5928, 2019.

[221] F. Komura, K. Okuzumi, Y. Takahashi, Y. Takakura, and M. Nishikawa, "Development of RNA/DNA hydrogel targeting toll-like receptor $7 / 8$ for sustained RNA release and potent immune activation," Molecules, vol. 25, no. 3, p. 728, 2020.

[222] Y. Ping, C. Liu, Z. Zhang, K. L. Liu, J. Chen, and J. Li, "Chitosan-graft-(PEI- $\beta$-cyclodextrin) copolymers and their supramolecular PEGylation for DNA and siRNA delivery," Biomaterials, vol. 32, no. 32, pp. 8328-8341, 2011.

[223] R. M. Raftery, D. P. Walsh, L. Blokpoel Ferreras et al., "Highly versatile cell-penetrating peptide loaded scaffold for efficient and localised gene delivery to multiple cell types: from development to application in tissue engineering," Biomaterials, vol. 216, p. 119277, 2019.

[224] Y. Nishida, S. Ohtsuki, Y. Araie et al., "Self-assembling DNA hydrogel-based delivery of immunoinhibitory nucleic acids to immune cells," Nanomedicine, vol. 12, no. 1, pp. 123130, 2016.

[225] M. Shin, J. H. Ryu, J. P. Park, K. Kim, J. W. Yang, and H. Lee, "DNA/tannic acid hybrid gel exhibiting biodegradability, extensibility, tissue adhesiveness, and hemostatic ability," Advanced Functional Materials, vol. 25, no. 8, pp. 12701278, 2015.

[226] D. J. Smith, G. A. Brat, S. H. Medina et al., "A multiphase transitioning peptide hydrogel for suturing ultrasmall vessels," Nature Biotechnology, vol. 11, no. 1, pp. 95-102, 2016.

[227] T. Yata, Y. Takahashi, M. Tan et al., "DNA nanotechnologybased composite-type gold nanoparticle-immunostimulatory DNA hydrogel for tumor photothermal immunotherapy," Biomaterials, vol. 146, pp. 136-145, 2017.

[228] Y. Shao, Z. Y. Sun, Y. Wang, B. D. Zhang, D. Liu, and Y. M. $\mathrm{Li}$, "Designable immune therapeutical vaccine system based on DNA supramolecular hydrogels," ACS Applied Materials \& Interfaces, vol. 10, no. 11, pp. 9310-9314, 2018. 